\title{
The Relation between Decadal Variability of Subtropical Mode Water and the North Atlantic Oscillation*
}

\author{
TERRENCE M. JoyCE \\ Woods Hole Oceanographic Institution, Woods Hole, Massachusetts \\ Clara Deser \\ Climate and Global Dynamics Division, National Center for Atmospheric Research, Boulder, Colorado \\ Michael A. Spall \\ Woods Hole Oceanographic Institution, Woods Hole, Massachusetts
}

(Manuscript received 14 October 1998, in final form 30 September 1999)

ABSTRACT

\begin{abstract}
The Bermuda station "S" time series has been used to define the variability of subtropical mode water (STMW) from 1954 to 1995 . This record, which shows decadal variability at a nominal period of about 12-14 $\mathrm{yr}$, has been used as a baseline for seeking correlation with large-scale atmospheric forcing and with decadal north-south excursions of the Gulf Stream position defined by the subsurface temperature at 200-m depth. A common time period of 1954-89 inclusive, defined by the data sources, shows a high degree of correlation among the STMW potential vorticity (PV), Gulf Stream position, and large-scale atmospheric forcing (buoyancy flux, SST, and sea level pressure). Two pentads with anomalously small and large STMW PV were further studied and composites were made to define a revised North Atlantic Oscillation (NAO) index associated with the decadal forcing. During years of low PV at Bermuda, the NAO index is low, the Gulf Stream is in a southerly position, and the zero wind stress curl latitude is shifted south as are the composite extratropical winter storm tracks, in comparison to the period of high PV at Bermuda. Because the NAO, Gulf Stream separation latitude, and STMW PV variations are in phase with maximum annually averaged correlation at zero year time lag, the authors hypothesize that all must be either coupled with one another or with some other phenomenon that determines the covariability. A mechanism is proposed that could link all of the above together. It relies on the fact that during periods of high STMW PV, associated with a northerly Gulf Stream and a high NAO, one finds enhanced production of mode water in the subpolar gyre and Labrador Sea. Export of the enhanced Labrador Sea Water (LSW) component into the North Atlantic via the Deep Western Boundary Current can influence the separation point of the Gulf Stream in the upper ocean once the signal propagates from the source region to the crossover point with the Gulf Stream. If the SST signal produced by the 100-km shift of the Gulf Stream along a substantial $(1000 \mathrm{~km})$ length of its path as it leaves the coast can influence the NAO, a negative feedback oscillation may develop with a timescale proportional to the time delay between the change of phase of the airsea forcing in the Labrador Basin and the LSW transient at the crossover point. Both a simple mechanistic model as well as a three-layer numerical model are used to examine this feedback, which could produce decadal oscillations given a moderately strong coupling.
\end{abstract}

\section{Introduction}

The most prominent type of subtropical mode water (STMW) in the North Atlantic is the $18^{\circ} \mathrm{C}$ water (Wor-

\footnotetext{
* Woods Hole Oceanographic Institution Contribution Number 9888.

Corresponding author address: Dr. Terrence M. Joyce, Woods Hole Oceanographic Institution, Mail Stop 21, 360 Woods Hole Road, Woods Hole, MA 02543.

E-mail: tjoyce@whoi.edu
}

thington 1959) found to the south of the Gulf Stream in the Sargasso Sea. This layer lies above the permanent pycnocline and is characterized by a vertically homogeneous layer that outcrops in late winter and is capped over during spring. Its temporal variability has been studied using the time series at Bermuda by Talley and Raymer (1982) and recently updated by Talley (1996), who noted some key characteristics (Talley 1996, Table 2 ): mean depth $=287 \mathrm{~m}$, mean potential density $=$ $26.45 \mathrm{~kg} \mathrm{~m}^{-3}$, and mean potential temperature and salinity of $17.88^{\circ} \mathrm{C}$ and $36.5 \mathrm{psu}$, respectively. Joyce and Robbins (1996) noted that the variability of the potential vorticity, $\mathrm{PV}=-(f / \rho) \rho_{z}$, at $300-\mathrm{m}$ depth (near mean 


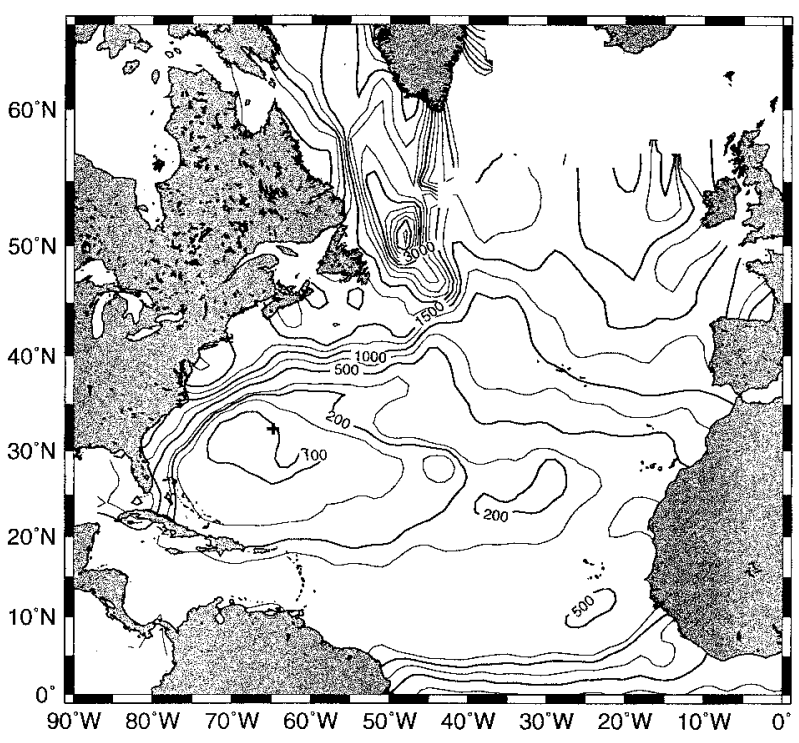

FIG. 1. Distribution of potential vorticity $\times 10^{-12}(\mathrm{~ms})^{-1}$ on the potential density surface $26.5 \mathrm{~kg} \mathrm{~m}^{-3}$ according to Lozier et al. (1995). A Gaussian spatial filter of $700 \mathrm{~km}$ has been applied to the gridded data before contouring. Bermuda is located at the " + " mark within the minimum.

depth of STMW at Bermuda) was anticorrelated with surface density changes. Thinking of purely diabatic processes for the formation of the STMW, one would have to make the near surface density larger in order to convectively mix the STMW, consistent with observations.

We expand on this theme in this study, first using the potential vorticity (PV) variability of the STMW from Joyce and Robbins and comparing this to decadal variations in the wintertime buoyancy flux at the surface and then to other atmospheric fields, including sea level pressure (SLP), which will inevitably invoke a pattern reminiscent of the North Atlantic Oscillation (NAO). A revised NAO index, keyed to the correlation with the PV signal will then be obtained. Finally, we will explore the nature of the atmospheric and oceanic signal in different NAO/STMW “epochs," concluding with comments on why the two signals are phased as they are with some speculation on a possible coupling mechanism.

\section{STMW variability and correlation with air-sea "forcing",}

We begin by noting that our data source for the atmospheric side of the interface is the da Silva and Levitus (1994) atlas of Consolidated Ocean-Atmosphere Data Sets, while the oceanic signal is predominantly from the station " $\mathrm{S}$ " time series at Bermuda, beginning in 1954 and extending to the present. The period of overlap of the two datasets is 1954-89, the last year available in da Silva et al. In a study of the historical hydrographic data in the North Atlantic, Lozier et al.

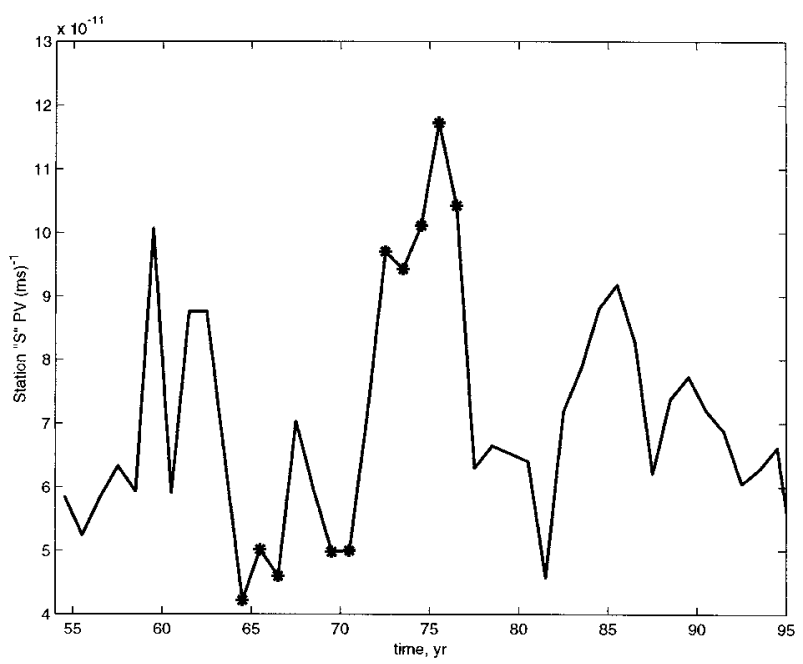

FIG. 2. Bermuda's station S time series of annually averaged STMW $\mathrm{PV}$ at 200-m depth according to Joyce and Robbins (1996). Five yr of extreme low and high values used in pentadal analyses are denoted by "*." In this and other figures, we have suppressed the leading "19" before the dates, all of which are in the twentieth century.

(1995) presented property maps of pressure, temperature, and PV on the $26.5 \sigma_{\theta}$ surface, nearly coincident with the core density of the STMW. The PV signal is reproduced here in Fig. 1 using a 700-km Gaussian filter similar in scale to that in da Silva et al. The PV distribution has an isolated minimum in which the island of Bermuda is located. Surrounding this minimum is higher PV water in the Gulf Stream to the north and the recirculation gyre to the south. This fact suggests that in the presence of downgradient eddy fluxes of PV, some process must be maintaining the minimum, namely, contact with the atmosphere and diabatic forcing in winter. We will return to this later, but point out that the Bermuda data is particularly well located for the monitoring of long-term variations in the STMW PV because, located well within the minimum, lateral gradients are small and horizontal advection of existing gradients by the ambient, mean, and time-dependent circulation is minimal. The PV signal at Bermuda (Fig. 2) is here seen to have a range of a factor of 2 from a low value near $5 \times 10^{-11}$ to $10 \times 10^{-11}(\mathrm{~ms})^{-1}$. This signal clearly shows decadal-type variations, with a climatological minimum value in 1964 and a maximum in 1975. We will later focus on these two extreme time periods in order to better understand the surface forcing.

Since the STMW lies sandwiched between the surface layer and the pycnocline, we might first look to the pycnocline depth as a major contributor to STMW thickness changes, especially since the pycnocline represents the maximum level of temperature and salinity variability in the water column (Joyce and Robbins 1996). A correlation coefficient value of -0.07 between the two, however, is far below a zero significance value of 0.3 for the time series. We can therefore reject the hypothesis that pycnocline depth, perhaps associated with 
interannual changes in wind stress curl (Sturges and Hong 1995), is responsible for the STMW thickness or PV signal.

We have correlated the PV time series at Bermuda with the wintertime (January-March) atmospheric data for buoyancy flux, SST, and SLP (Fig. 3, left panels). Within the western subtropical gyre, PV and buoyancy flux are negatively correlated; when the buoyancy flux is positive, the ocean gets denser and the PV decreases. The buoyancy flux anomaly in the Labrador Sea is positively correlated with PV at Bermuda; in fact, the correlation coefficient is largest just east of Newfoundland. Dickson et al. (1996) have noted that time periods of large buoyancy flux in the Labrador Sea are associated with periods of low buoyancy flux in the Sargasso Sea and it is not surprising that the STMW signal reflects this. Cayan (1992) also showed the same phase difference between the eastern and western subtropics as we find, but using the NAO index as a metric, not the STMW variability. We note the overall spatial similarity between the SST and buoyancy flux patterns and that the western subtropical gyre is cold when PV is low and warm when PV is high (Fig. 3, middle panels), with a maximum SST response not in the region of the STMW forcing to the northeast of Bermuda (see buoyancy flux composite anomaly), but rather near where the Gulf Stream is located "upstream" of the maximum buoyancy forcing. Because of the significant correlation between the PV signal and the SST off the U.S. East Coast, there is a similarity in the time series of PV and the SST anomaly in the storm formation region (SFR) shown by Sutton and Allen (1997). However, 1965, a year of low PV at Bermuda is not a year of low SST in the SFR, so there are some differences (The SLP composite discussed next is different in the two analyses). The sense of the correlation of the STMW PV and the SLP (Fig. 3, lower panels) reaffirms the importance of the NAO; with extrema located between Greenland and Iceland in the north and southwest of the Azores in the subtropics. We have shown all correlations with no time lag, but have examined the sensitivity to the atmosphere leading or lagging the ocean by $1 \mathrm{yr}$. The correlation coefficient is reduced in both cases from that at zero lag. Thus, the STMW is responding "in phase" with the atmosphere, at least in terms of interannual anomalies.

\section{Air-sea exchange during two climatological extrema}

We will now examine the atmospheric conditions during the two climatological extrema in the STMW PV. We select (based on Fig. 2) the $5 \mathrm{yr}$ of minimum PV (1964-66, 1969, and 1970) predominantly in the 1960s with 5 yr of maximum PV in the 1970s (1972-76). We have not selected the 1981 period of low PV because it was an isolated event in time. Our desire here is to use these "pentads" very much like Levitus (1989), who defined warm and cold pentads based on the pycnocline history at Bermuda in order to maximize our signal-tonoise ratio and to see the spatial structure of the oceanic anomalies throughout the North Atlantic. In our case, we will use the STMW PV signal and look for anomalies in the atmospheric forcing.

We first examine the buoyancy flux (Fig. 3, upper right panel) that is closely tied to the PV forcing. During low PV years, the maximum buoyancy forcing is to the northeast of Bermuda, a region where the STMW is thought to form (Fieux and Stommel 1975). In contrast, the buoyancy anomaly during high PV years is negative in the Sargasso Sea with a total swing of about $3 \times$ $10^{-5} \mathrm{~kg}\left(\mathrm{~ms}^{3}\right)^{-1}$ between the two extrema. We also show SST and SLP anomalies for the low-minus-high PV years (Fig. 3, middle and lower right panels) and remark that the SST is anomalously cool throughout the western subtropical gyre with an amplitude of about $-0.5^{\circ} \mathrm{C}$. In the low-minus-high composite, atmospheric pressure is lower near the Azores and higher between Greenland and Iceland by about 9 and $13 \mathrm{mb}$, respectively. We have not shown the net heat flux, but it behaves very much like net buoyancy flux, but with a different sign. In fact, the contribution of the salinity forcing to the buoyancy flux reinforces the net heat flux within the western subtropical gyre, but is generally smaller; in low PV years the ratio of these two terms is 0.05 , while it is 0.32 in high PV years. If buoyancy (or heat) flux is driving SST variability as is suggested by the work of Cayan (1992) and Deser and Timlin (1997), one might expect the composite SST pattern to reflect that of the composite forcing. The shifting of the SST signal "upwind" of the forcing and not downstream in terms of oceanic advection may suggest (ignoring spatial variations of mixed layer depth) more than a simple passive response of the ocean to the atmosphere. We have also examined the point by point correlation between net heat flux and SST anomalies in the region. Over most of the region they are positively correlated, supporting the hypothesis of ocean following atmosphere. However, in the region where the Gulf Stream leaves the coast, the correlation is negative. This suggestion of ocean leading atmosphere was noted by Battisti et al. (1995) using a similar dataset and demonstrated by Halliwell (1998) using an ocean GCM.

\section{A revised NAO index}

The low-minus-high PV composite pattern for SLP (Fig. 3, lower right) is very similar to Hurrell's (1995) NAO pattern, except that the subtropical Atlantic center is shifted about $30^{\circ}$ farther west and about $5^{\circ}$ farther south. It is also shifted about $10^{\circ}$ east compared with the composite pattern of Sutton and Allen (1997). Using the SLP composite as a guide, we constructed a revised NAO index, defined as the normalized SLP in the Icelandic area minus that in the subtropics. The NAO and normalized PV records are plotted in Fig. 4, both un- 

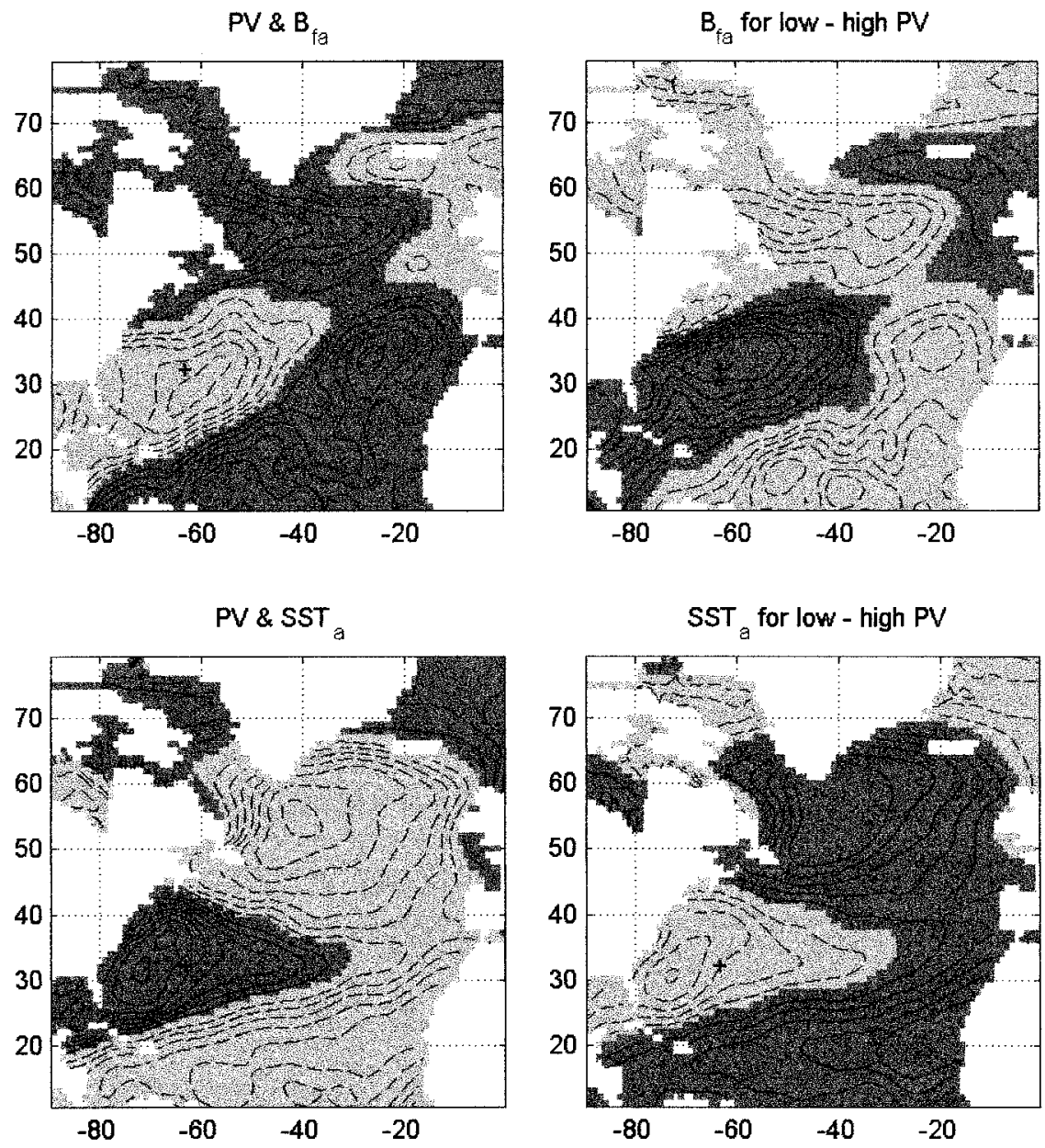

PV \& SLP
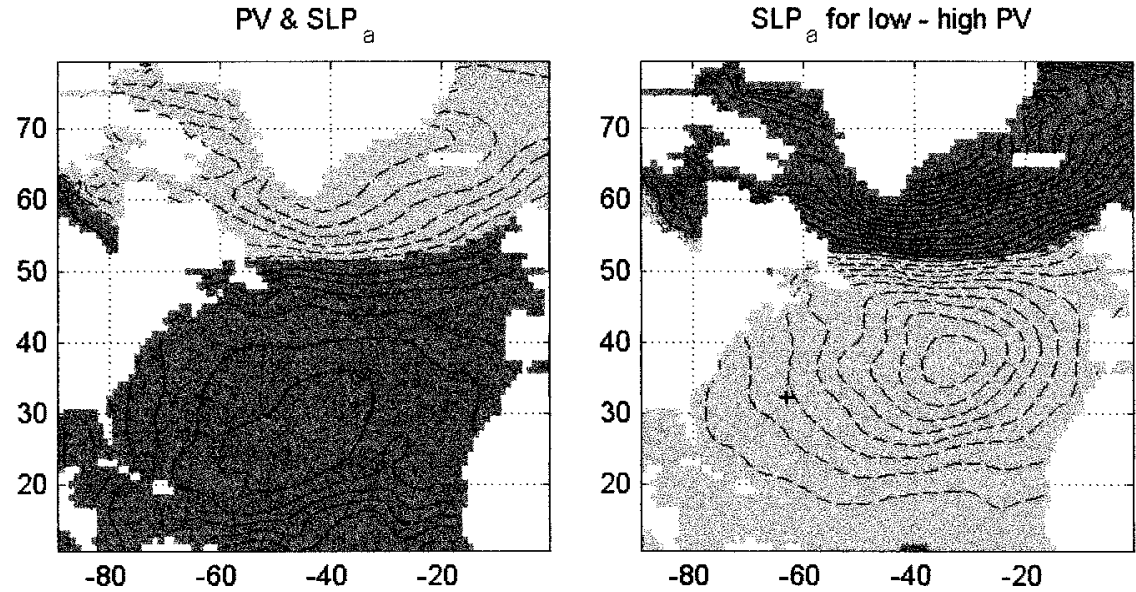

FIG. 3. Correlation coefficient (dashed for negative, solid for positive) for STMW PV with buoyancy flux (upper left), SST (middle left), and SLP (lower left). Contour interval is 0.1. The 95\% significance level varies spatially due to changes in the integral timescale of the fields. In general, this level varies between 0.45 and 0.5 over most of the region. For low-minus-high PV pentads, the wintertime anomalies of buoyancy flux [upper right, contour interval is $0.5 \times 10^{-5}$ $\mathrm{kg}\left(\mathrm{ms}^{3}\right)^{-1}$ ], SST (middle right, contour interval $0.2^{\circ} \mathrm{C}$ ), and SLP (lower right, contour interval $1 \mathrm{mb}$ ). Dark gray areas indicate positive anomalies and correlations. The position of Bermuda is denoted by "+." 

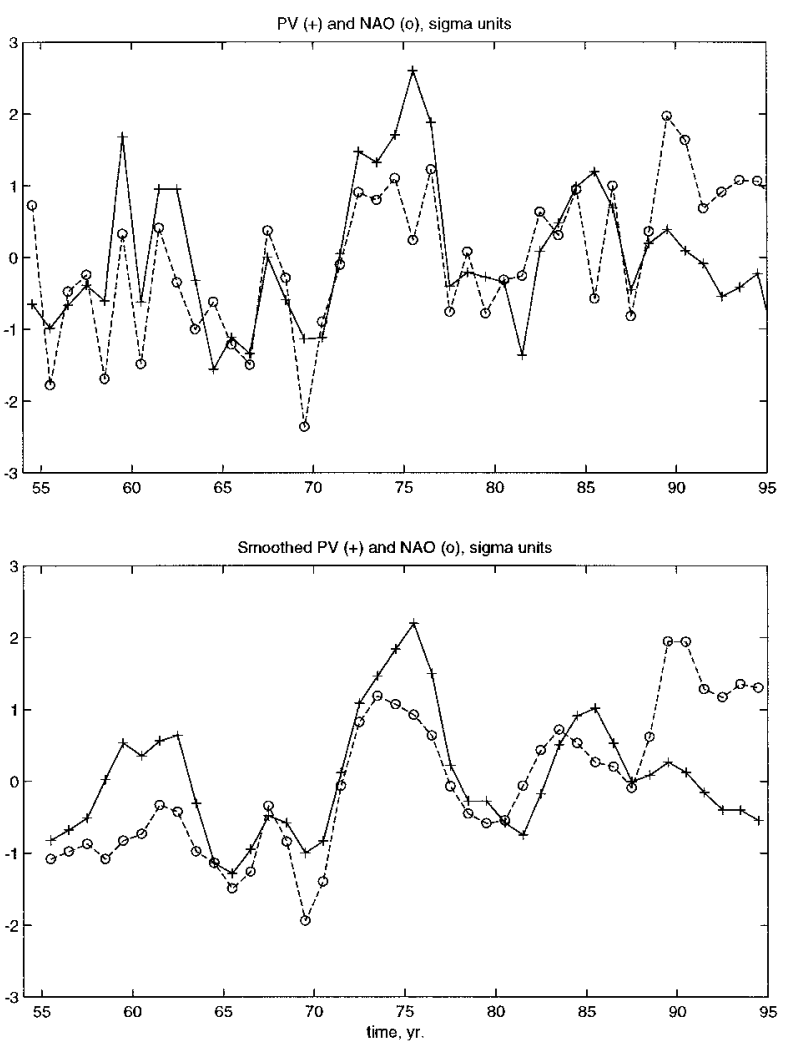

FIG. 4. Normalized PV (solid lines) and wintertime NAO index (dashed lines). (top) Unsmoothed and (bottom) has 1-2-1 filter applied.

smoothed (top) and smoothed with a 3-point binomial filter in time (bottom). The match is quite good in the unsmoothed records, except that there is an upward trend in the NAO that is not present in the PV record (this aspect is even more apparent in the smoothed version). The correlation between the smoothed (unsmoothed) NAO and PV is 0.76 (0.70) up through 1990. The lagged correlation of the unsmoothed NAO and PV time series clearly indicates a maximum correlation at zero lag. We will discuss this further after we discuss the Gulf Stream in the next section. If the years 199095 are included, the unsmoothed correlation of 0.70 is reduced to 0.52 , owing to the increase in NAO index in recent years with little change in the STMW PV. Talley (1996) has presented a similar visual comparison of NAO and PV records, but did not quantify the strength of the relationship.

\section{Gulf Stream path from subsurface thermal data}

To investigate the issue of interannual changes in Gulf Stream position, we have used subsurface temperature data from the Levitus (1994) atlas of MBT and XBT data for the common time period of 1954-89. The temperature at 200-m depth has been used for some time as defining the region of strong flow of the Gulf Stream
(Fuglister 1955). The $15^{\circ} \mathrm{C}$ isotherm at $200 \mathrm{~m}$, representing an isotherm in the center of the strong horizontal gradient of the Gulf Stream, lies just to the north of the maximum flow at the surface (Fuglister 1963) and is a convenient marker for the northern "wall" of the stream. This has been confirmed by the time series of Halkin and Rossby (1985) near $73^{\circ} \mathrm{W}$ in which temperature and velocity profiles were placed in a streamoriented coordinate system and averaged. Since the maximum depth of the wintertime mixed layer west of $60^{\circ} \mathrm{W}$ in the region is less than $200 \mathrm{~m}$ (Qiu and Huang $1995)$, this depth is not directly affected by diabatic processes. Though the $15^{\circ}$ isotherm surfaces north of the Gulf Stream in winter, the property and velocity variations on the outcropping isopycnals in the upper ocean remain large for $2000 \mathrm{~km}$ after the Gulf Stream leaves the coast (Bower et al. 1985), making this estimate of Gulf Stream location $\left[T(200)=15^{\circ} \mathrm{C}\right]$ relatively unaffected by surface diabatic processes. Use of a deeper level (e.g., $300 \mathrm{~m}$ ) produces similar results, but effectively eliminates the first decade of our time series since the mechanical bathythermograph dataset did not extend that deep. Rossby and Gottlieb (1998) have examined repeated velocity sections made across the Gulf Stream near $70^{\circ} \mathrm{W}$ from 1993 to mid-1997. They have found little interannual variability in the surface velocity, transport of the high velocity core, and the width over time, while they have observed interannual changes in the latitude of the flow. Thus, the dominant observable in the interannual variability of the surface Gulf Stream is its location. We will now examine this using the archive of subsurface temperature observations.

In the region of interest, between latitudes of $33^{\circ}$ and $43^{\circ} \mathrm{N}$ and between the longitudes of $45^{\circ}$ and $76^{\circ} \mathrm{W}$, a total of 7059 (3300) observations were found during the low (high) PV period. The results have been presented first at a selected longitude $\left(65^{\circ} \mathrm{W}\right)$, taking all available data within $\pm 2.5^{\circ}$ of longitude, and plotting the time series of 200-m temperature (Fig. 5, top). We have chosen this longitude because it is one of large interannual variation in the Gulf Stream path (bottom). The time series shows north/south oscillations of the Gulf Stream that look very similar to the NAO index above (Fig. 4) and confirms a southward shift of the Gulf Stream during low NAO periods and a northward shift (compared to the long-term mean) during high NAO periods. Looking south of the stream, we also see that when the stream is south, the $T(200 \mathrm{~m})$ temperatures are low, with the obverse holding when the stream is north. The thermal signals in the Sargasso Sea cannot be induced by shifts in the Gulf Stream path, but must be due to enhanced cooling/heating in the Sargasso Sea as discussed by Molinari et al. (1997). The phasing of the air-sea forcing and the subsurface temperatures are such as to reinforce the sign of the anomaly (Deser and Blackmon 1993) over the areas of the North Atlantic away from the Gulf Stream. The envelope of annual Gulf Stream positions is based approximately on 1000-2000 observations per 

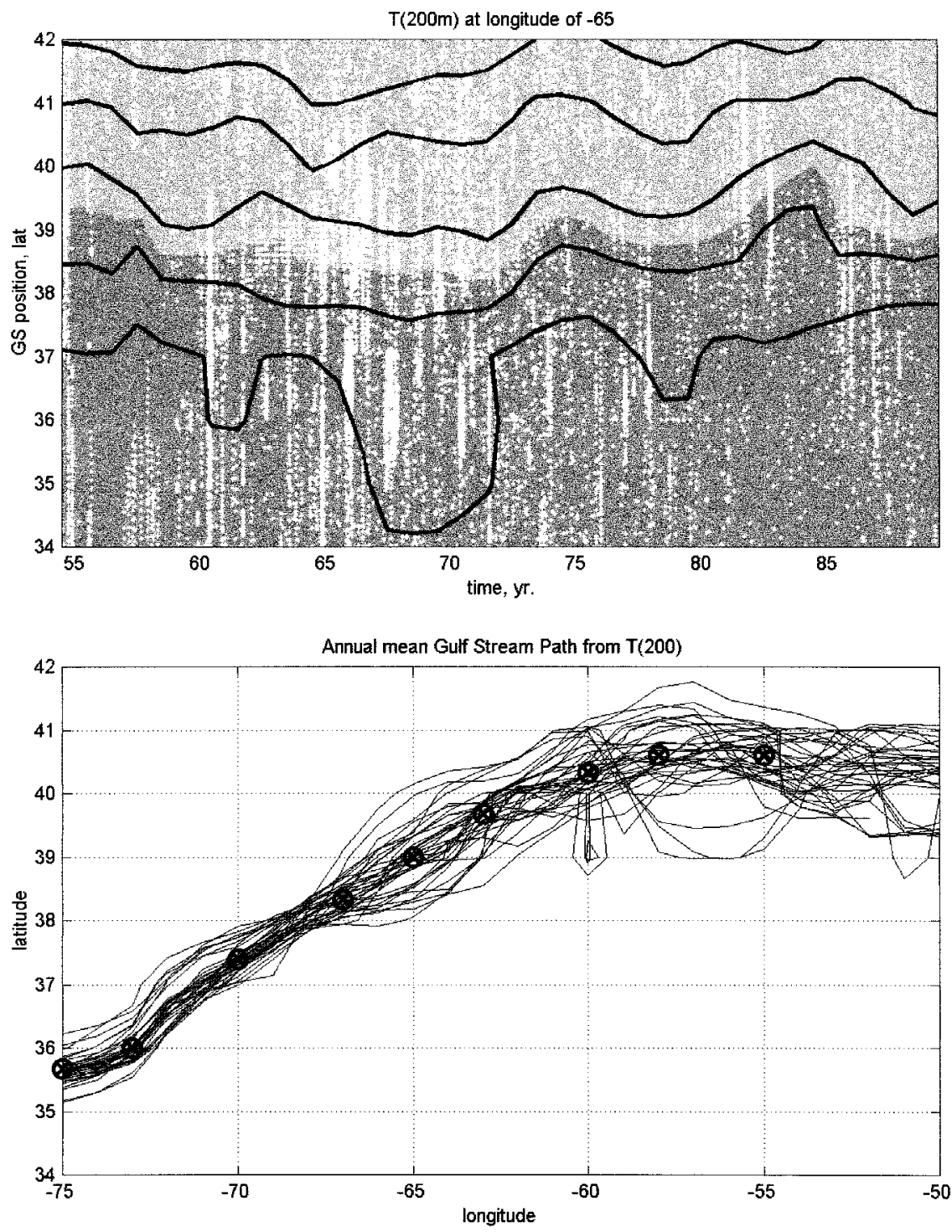

FIG. 5. Annually averaged temperature at 200-m depth vs latitude and time (top) with a contour interval of $2^{\circ} \mathrm{C}$. Temperatures less (greater) than $15^{\circ} \mathrm{C}$ are shaded in light (dark) gray. The envelope of 36 annual positions of the Gulf Stream based on T(200) data from 1954-89 (bottom). The annual mean position is based on the $15^{\circ} \mathrm{C}$ isotherm at $200 \mathrm{~m}$. Also shown are the locations where subsequent EOF analysis was done using the $T(200)$ dataset. EOF analysis east of $60^{\circ} \mathrm{W}$ did not indicate any contribution to the lowest (common) EOF mode.

year and shows a growing meandering pattern downstream from Hatteras (Fig. 5, bottom). There is a suggestion of a node near $68^{\circ} \mathrm{W}$, which is close to that found near $69^{\circ} \mathrm{W}$ by Cornillon (1986) using satellite SSTbased 2-day maps of GS path over a 30-month period. We can see that certain longitudes (e.g., $65^{\circ} \mathrm{W}, 57^{\circ} \mathrm{W}$ ) have a larger envelope of variability than others.

We also show the mean path of the Gulf Stream, defined by the $T(200 \mathrm{~m})$ temperature during the $5-\mathrm{yr}$ pentads of low and high PV at Bermuda (Fig. 6, upper panel) that shows a difference in mean position depending upon the PV signal at Bermuda. The total latitudinal range is about a half degree over most of the region from where the stream leaves the coast to about $60^{\circ} \mathrm{W}$, with a slightly larger range of about $100 \mathrm{~km}$ near $65^{\circ} \mathrm{W}$, where we have shown a selected time series. There is a significant difference in the Gulf Stream path between $62^{\circ}$ and $72^{\circ} \mathrm{W}$ during the two periods.

Clearly a north/south shift in the Gulf Stream position will create temperature anomalies at 200-m depth as well as at the ocean surface without any atmospheric intervention. The sense of the observed shift is such that enhanced cooling over the Gulf Stream-Sargasso Sea during the low PV epochs will reinforce the SST and subsurface temperature signal due to Gulf Stream position. The fact that maximum temperature differences 

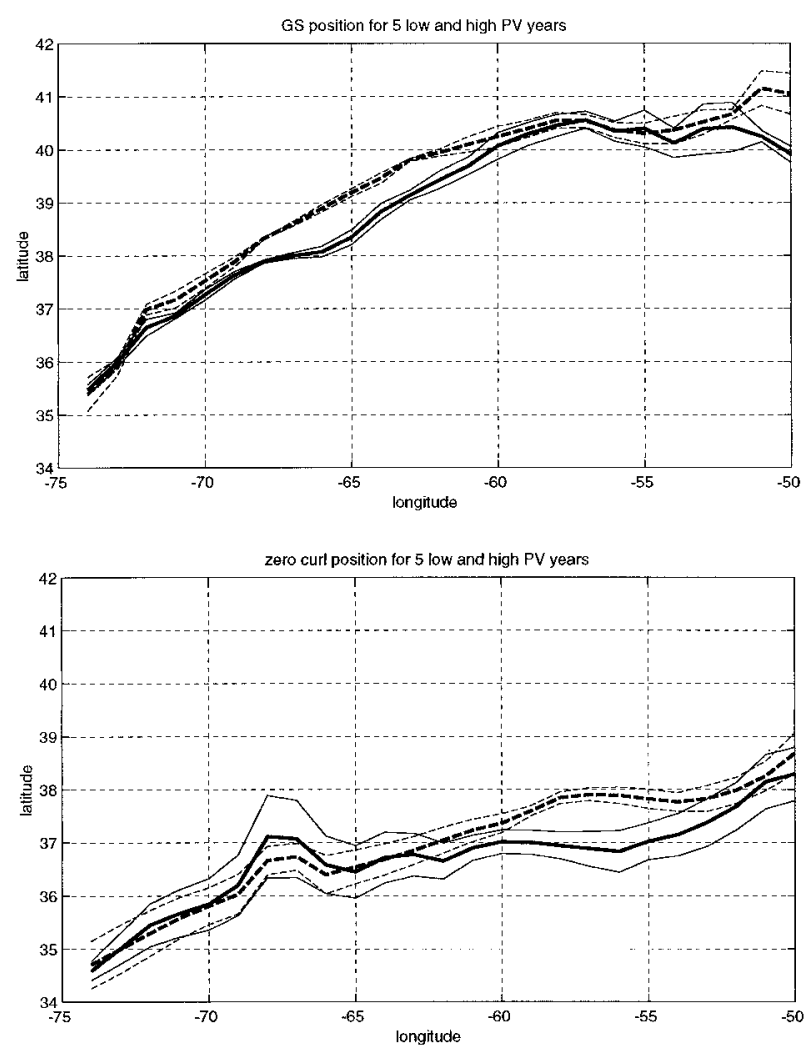

FIG. 6. Mean position of $15^{\circ} \mathrm{C}$ isotherm for two pentads of low and high PV (upper panel) and zero wind stress curl (lower panel) In both cases the standard error in the mean was used to construct a significance $(1 \sigma)$ envelope for each of the two periods. Considerable more variance was found in the wind curl data. In both panels, heavy solid (dashed) lines denote low (high) PV pentads.

at 200-m depth between the two periods are often found near the position of the Gulf Stream suggests that both the oceanic response to enhanced cooling together with the southerly Gulf Stream position are acting in concert to generate SST and upper ocean thermal anomalies over a longitudinal distance of almost $1000 \mathrm{~km}$. One might anticipate a similar situation in the North Pacific along the Kuroshio Extension, although model/data comparisons there have focused mainly on changes in the strength of the westerlies and gyre circulation and the SST fields (Latif and Barnett 1994).

Halliwell and Mooers (1979) used 2 yr of Gulf Stream frontal analysis data in their study of GS variability. While their work focused on monthly timescales, they did suggest that large-scale shifts of the position were one of the dominant modes of interannual variability. This has been further studied by George and Taylor (1995) and Taylor (1996) in the context of zooplankton variability in English lakes. Their hypothesis is that Gulf Stream (GS) position will affect atmospheric forcing over the British Isles (although they considered mainly SLP as an index, not buoyancy or heat flux) and thus when lakes will stratify in the spring. Winters of high heat loss or buoyancy flux should be correlated with

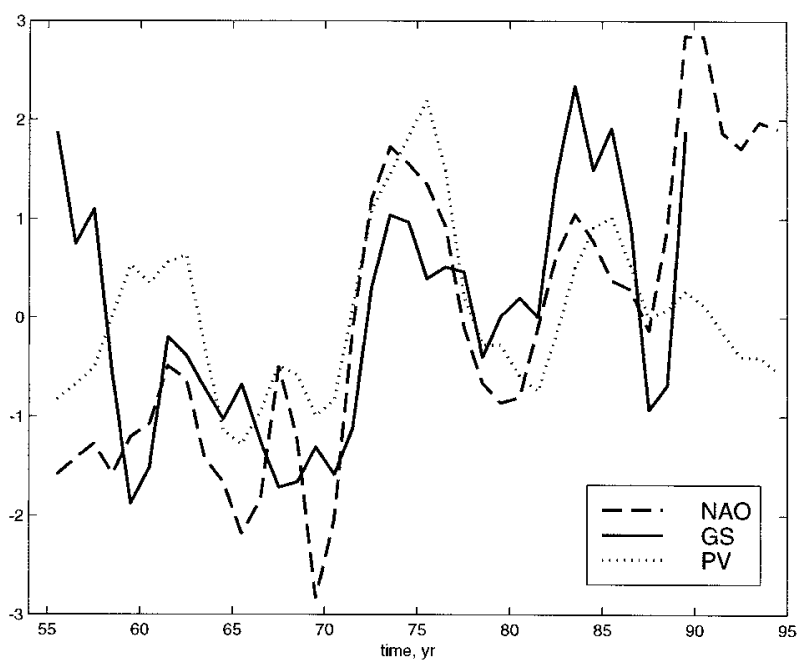

FIG. 7. Gulf Stream index for coordinated north-south shifts in position based on nine selected points along the Gulf Stream path between $75^{\circ}$ and $55^{\circ} \mathrm{W}$ and the temperature at 200-m depth. The covariance (not correlation) matrix for the nine temperature points was used to construct the EOFs, in which more than $50 \%$ of the interannual variance was contained in north-south changes of the same sign at all nine locations. Periods when the GS is north have positive values for the index. Also shown are the smoothed NAO and STMW PV indices (Fig. 4, bottom) for the same time period.

enhanced nutrient input into the surface layer, a delayed restratification and with elevated zooplankton concentrations in late spring. Since southerly GS positions are associated with enhanced STMW formation, above-average wintertime forcing over the Sargasso Sea and the United Kingdom (see Fig. 3, upper panel), suggests that an important source of atmospheric variability exists that would explain the zooplankton record. Taylor and Stephens (1998) develop further the idea that coordinated north-south shifts in the Gulf Stream on interannual timescales are correlated with the NAO.

In order to better compare our results with theirs, we have selected 9 locations along the Gulf Stream path between $75^{\circ}$ and $50^{\circ} \mathrm{W}$ and used an EOF analysis of the $T(200 \mathrm{~m})$ data to determine an index for the Gulf Stream position (these positions are shown in Fig. 5, bottom; they coincide with the mean path of the Gulf Stream based on the $15^{\circ}$ isotherm). Based on the yearly averages, the time series (Fig. 7) of the most energetic mode (more than $50 \%$ of variance) represents an in phase north-south shift in position that is correlated $(r=0.7)$ with our NAO index (Fig. 8) with maximum correlation at lag 0 and +1 yr (GS following the NAO). A similar result is obtained when the standard NAO index (normalized SLP difference between the Azores and Iceland) is used in place of our "revised" NAO index (not shown). We note that this result differs from that of Taylor and Stephens (1998) who used a Gulf Stream index based on monthly frontal analyses of satellite SST imagery during the period 1966-96. They found a maximum correlation when their GS index lags the NAO 


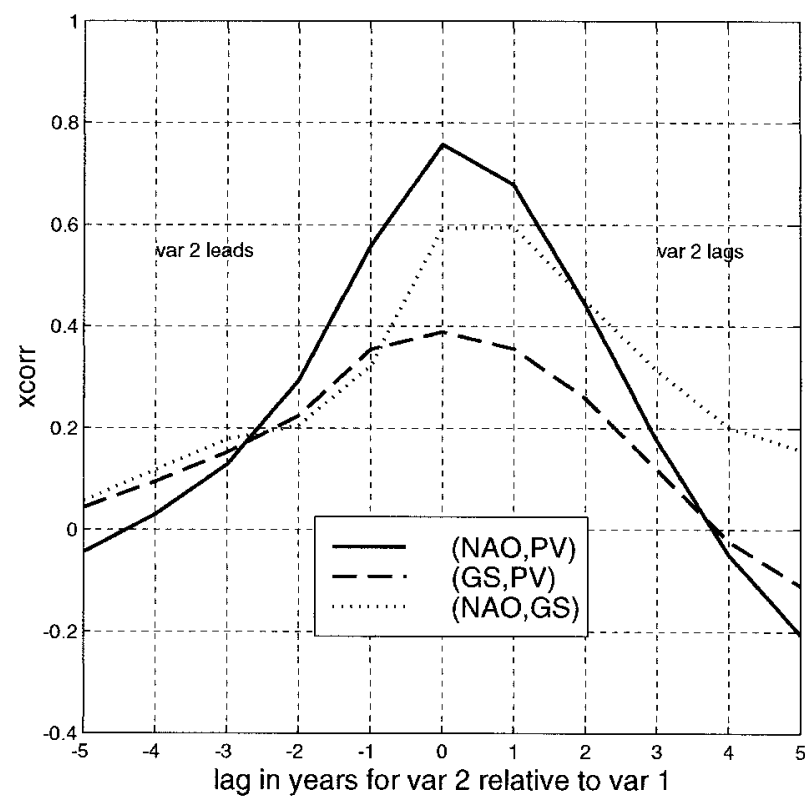

FIG. 8. Time-lagged cross correlation of the three variables shown in Fig. 7 was done over their common time period of 1955-89 inclusive. We find the largest correlation at zero years lag for all pairs, except for the GS-NAO where the cross correlation is high for both zero and 1-yr lag of the GS compared to the NAO. Significant correlations must exceed $0.45-0.5$ for the three combinations, which suggests that the GS and PV are not directly linked to each other, only through the NAO.

by 2-3 yr. As shown in the appendix, our GS index and that of Taylor and Stephens (1998) are very similar from 1975 onward (and yield similar lag correlations with the NAO), but disagree prior to 1975 . We attribute the difference between the two GS records in the early years to peculiarities in the frontal analysis product, although we cannot substantiate this claim. Given the strong simultaneous correlation between our index of the GS and the NAO, we do not interpret the NAO as simply forcing a delayed response in GS position (as do Taylor and Stephens 1998), but leave open the possibility that the two may also vary in phase.

\section{Wind variability and the zero wind stress curl location}

Steady, homogeneous, linear and nonlinear models of the wind-driven circulation (Pedlosky 1979) indicate that the point of separation of the western boundary current from the coast is governed by the latitude of the zero wind stress curl or the latitude at which the westward interior flow feeding the western boundary current vanishes. While other factors control the point of separation in the real ocean, we thought it worthwhile to show how these variables vary in time for the Gulf Stream. We have used the da Silva data to estimate the wind stress curl and hence the interior Sverdrup transport and plotted this as a function of time near the west-

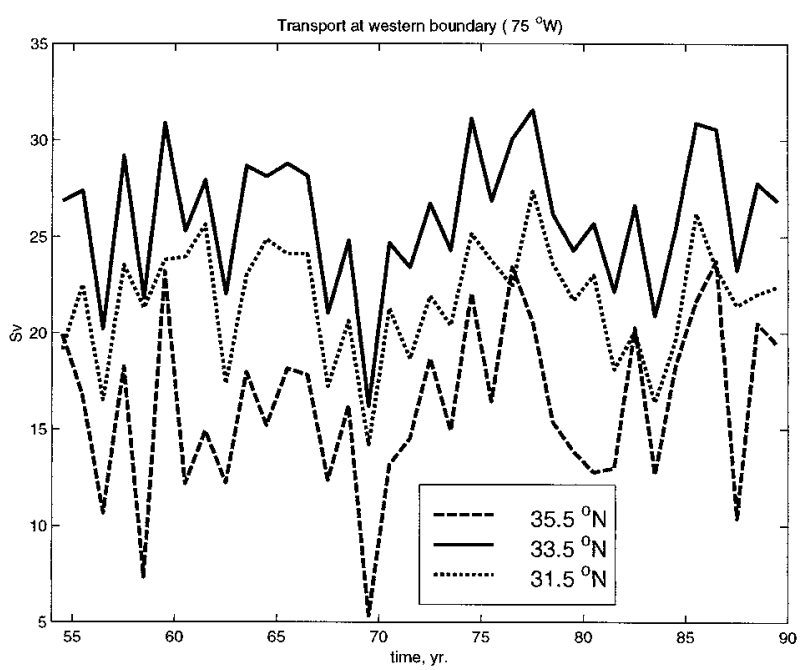

FIG. 9. Transport $(\mathrm{Sv})$ required at the western boundary to return the Sverdrup interior flow at three selected latitudes near the western boundary. This assumes a quasi-steady balance and is shown only to indicate the variability in the wind forcing and the latitude dependence near the latitude of maximum Sverdrup transport.

ern boundary $\left(75^{\circ} \mathrm{W}\right)$ for three latitudes. At this longitude, the north wall position is at about $35.5^{\circ} \mathrm{N}$ (Fig. 5 , bottom). The maximum in the Sverdrup transport (plotted with opposite sign in Fig. 9) occurs at $33.5^{\circ} \mathrm{N}$ and one can see that despite an interannual standard deviation of $\pm 4 \mathrm{~Sv}\left(1 \mathrm{~Sv} \sim 10^{9} \mathrm{~kg} \mathrm{~s}^{-1}\right)$ about the yearly mean values, the interior Sverdrup flow is always westward into the boundary current south of $33.5^{\circ} \mathrm{N}$, but is eastward at the latitude of the GS north wall (after separation). From $33.5^{\circ} \mathrm{N}$, the transport drops off more quickly toward the north than the south. In fact, the gyre boundary, defined by the latitude of the zero wind stress curl, is rapidly approached and nearly coincident with both the maximum in the meridional Sverdrup transport and the zero wind curl latitude at the western boundary. The near coincidence of these with the position of the separated Gulf Stream is a feature that Behringer et al. (1979) attributed to an enhancement of the zonal wind stress over the warm, surface GS water. For the low (high) PV years when the mean Gulf Stream location is to the south (north), the zero wind curl position (Fig. 6 , bottom) is also to the south (north). We therefore see both a small difference (at the 95\% level) in the winddriven forcing at $33.5^{\circ} \mathrm{N}$ during the low/high PV epochs: 25.2-27.8 Sv, as well as a significant difference in the latitude of the zero curl line downwind of the Gulf Stream shift. If the zero curl line also defines the position of the maximum westerlies, then one sees them shifting meridionally with about the same magnitude and with a similar (but displaced) longitudinal structure as the Gulf Stream, during the different STMW epochs.

The Taylor and Stephens work, which found a delay between the Gulf Stream latitude and the NAO index, made use of a paper by Gangopadhyay, Cornillon, and 
Watts (1992, hereafter GCW). They used a ParsonsVeronis two-layer model with the lower layer at rest to study the Gulf Stream separation latitude, which was estimated locally near the coast in GCW as the latitude where the GS path crossed the 2000-m isobath. A delayed, wind-driven response in the two-layer case was suggested by GCW in good agreement with the observations for the period 1979-88. The sense of this estimate is that a larger Ekman transport (high NAO) translates into a lower latitude of separation at a time lag associated with the long, baroclinic Rossby wave adjustment (several years). For the time period of their study, this phase lag results in the Gulf Stream being in a northern position when the NAO index is high. We show later that a similar delay in the Gulf Stream position may result from consideration of the thermohaline circulation, which is not included in the model of GCW.

\section{Atmospheric storm track variability}

To further characterize the low level atmospheric circulation during low and high PV winters, we have investigated storm track variability based upon a dataset of extratropical cyclone frequencies (U.S. Navy and Dept. of Commerce, 1996) obtained from the National Climate Data Center (NCDC). The cyclone positions (based upon sea level pressure and given to the nearest tenth of a degree) were binned into $2^{\circ} \times 2^{\circ}$ grid boxes and total area-weighted counts formed for each winter season (January-March) during the period 1966-95. The storm frequencies were further smoothed in the zonal and meridional directions with a 3-point binomial filter.

The distribution of cyclones for the low and high PV winters is shown in Fig. 10 superimposed upon the corresponding SST fields. Since only 3 yr (1966, 196970) contribute to the low PV composite, we have multiplied the storm frequencies by five-thirds to allow for a direct comparison with the high PV composite; there are no significant differences in the total number of storm counts in the two periods after normalization. In the low PV winters, the storm track is most intense along the Gulf Stream between Cape Hatteras and Newfoundland. East of $50^{\circ} \mathrm{W}$, the cyclones move nearly due eastward toward Europe, with little storm activity north of approximately $50^{\circ} \mathrm{N}$. In the high PV composite, the storm track extends northeastward from Cape Hatteras towards Iceland. Rogers (1990) presented qualitatively similar storm frequency distributions based on nine winter months with extreme NAO values.

The difference in storm frequencies (Fig. 10, lower panel) between low and high PV winters has been superimposed on the mean storm frequency based on the whole period 1966-95. Relative to the low PV years, high PV years exhibit significantly more storms in the northeast Atlantic and significantly fewer storms to the south. In high PV years, there is also a reduction in the number of storms over the Gulf Stream, the main region
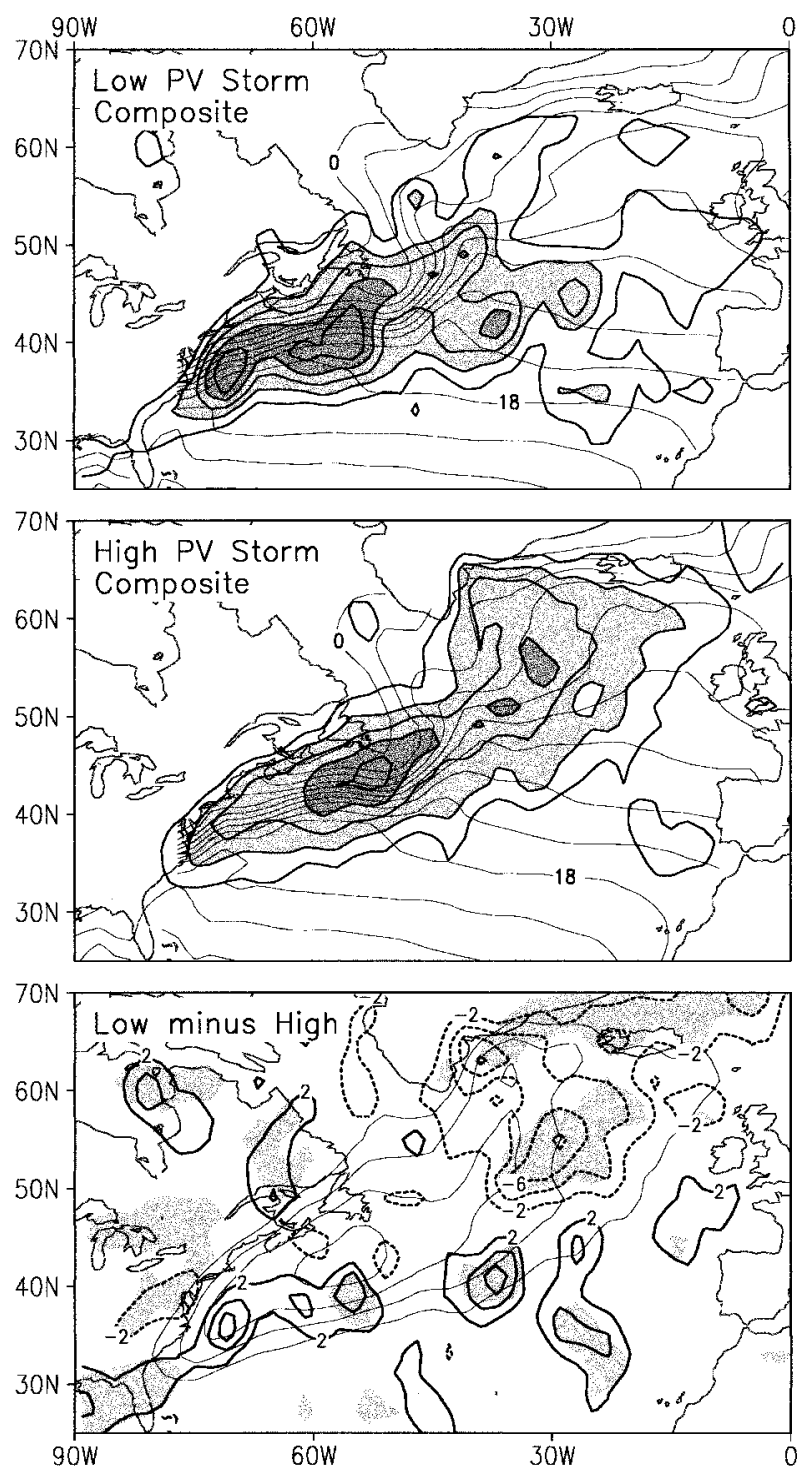

FIG. 10. Cyclone count totals for the high (upper panel) and low (middle panel) PV composites normalized to $5 \mathrm{yr}$ showing shades of gray (with a contour interval of 2) for the number of wintertime storms in a $2^{\circ} \times 2^{\circ}$ box and contours for the associated composite wintertime SST (from Reynolds). Cyclone count differences (lowhigh, contour interval is 2) for the two wintertime composites are plotted on top of the distribution of mean storm track distribution based on the 1966-95 period, but shown for an average 5-yr period (lower panel). Shaded regions denote significantly higher or lower storm counts compared to the mean.

of Atlantic cyclogenesis. The latitudinal distribution of storm totals over the Gulf Stream for the low and high PV winters is shown in Fig. 11. The maximum storm frequencies are greater and located approximately $2^{\circ}$ farther south in the low PV years compared to the high PV years. This latitudinal shift in storm activity is reminiscent of the north-south shift in the Gulf Stream position documented in section 5 .

The pattern of storm frequency change (Fig. 10) is 


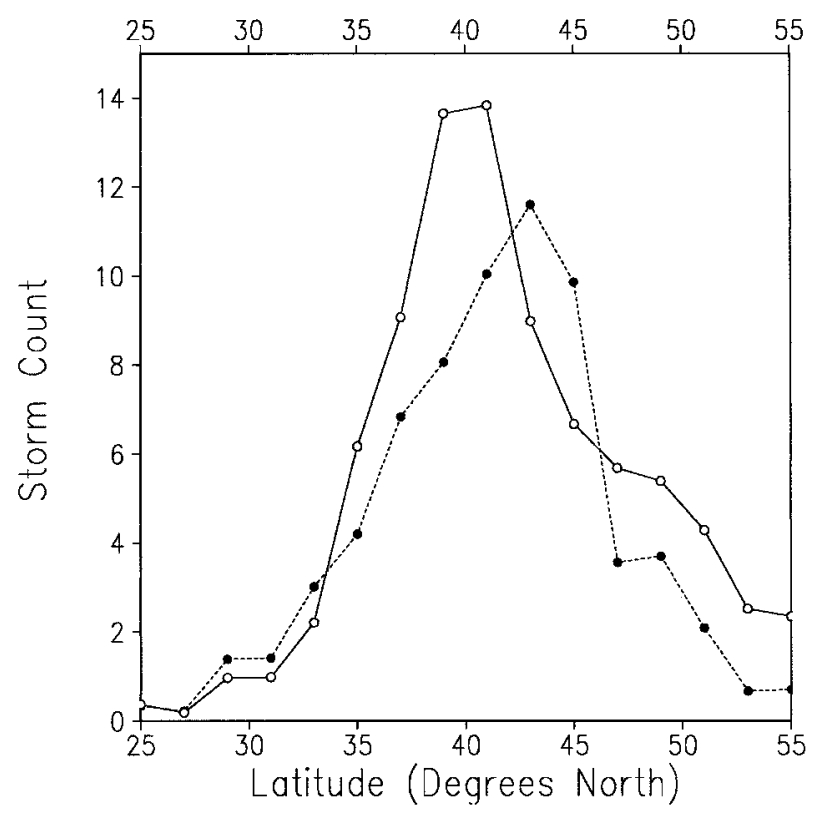

FIG. 11. For each of the two composite periods, storm track distributions have been plotted against latitude for a longitude band of $67^{\circ}-55^{\circ} \mathrm{W}$. The solid line is for low PV years and dashed line for denotes high PV years.

broadly similar to that shown in Serreze et al. (1997); however, the latitudinal shift in storm track location along the Gulf Stream was not apparent in their analysis. We recognize that the results presented in Figs. 10, 11 are based on a small sample size. To confirm the cyclone count signals associated with the NAO, we performed a regression analysis between the full storm frequency inventory and the NAO records based on the period 1966-95 with similar results (not shown) to those based on the more limited high and low PV composites. The most obvious relation between the effects of storm tracks and the ocean signal is the enhanced cooling of the STMW in the Sargasso Sea during a southerly storm track and enhanced cooling of the Labrador Sea Water (LSW) due to cold air outbreaks on the back side of lows travelling on a more northeasterly storm track. The storm track and associated large-scale atmospheric circulation may in turn be sensitive to the SST anomalies, in particular to shifts in the position of the Gulf Stream via changes in air-sea heat fluxes (cf. Venzke et al. 1999; Rodwell et al. 1999).

\section{Discussion}

We summarize the anomalous conditions during low and high PV years for the STMW in Table 1. Next we turn to some dynamical issues which emerge as a result of the various correlations associated with the quantities in the table.

\section{a. Why are PV variability and forcing in phase?}

Suppose PV is a quasi-conservative quantity obeying an equation of the following form

$$
d(\mathrm{PV}) / d t+\lambda \mathrm{PV}=F,
$$

where $\lambda \mathrm{PV}$ represents a relaxation process and $F$ diabatic forcing. The form of the equation is chosen to follow the Frankignoul and Hasselmann (1977) investigation of long-term SST signals generated by air-sea forcing. For a subsurface, isolated, low PV anomaly in contact with the atmosphere over part of the year/region, downgradient eddy fluxes of PV will contribute to $\lambda$. We have already noted that pycnocline displacement is uncorrelated with PV variability of the STMW, thus we do not expect vertical advection of PV to play a significant role. In fact, since the vertical gradient of PV at the depth of the STMW vanishes, vertical advection at that level vanishes altogether. Similarly, if mean horizontal flow lines are parallel to constant PV lines (consistent with the Lozier et al. PV and streamfunction maps), then mean horizontal advection is also not a factor. The remaining terms are time rate of change, forcing, and dissipation. In this limit, the low-frequency response of the above will be such that $\lambda \mathrm{PV}=F$, and the PV and forcing fields are in phase. For shorter timescales (or higher frequencies) the balance becomes $(\mathrm{PV})_{t}$ $=F$, and $\mathrm{PV}$ lags $F$ in phase by $90^{\circ}$. The fact that diabatic forcing and PV variability of the STMW are in phase, suggests that $\lambda \gg(1 \mathrm{yr})^{-1}$ and the system is highly damped on annual timescales, much like SST. If the forcing is diabatic and the relaxation process is eddy flux of PV with a mixing coefficient of $\kappa$ (Rhines and Young 1982), then the highly damped balance in (1) can be approximated

$$
-\kappa \nabla^{2} \mathrm{PV}=-\frac{f}{g \rho_{0} H^{2}} B_{f},
$$

where we have now replaced the idealized forcing with

\begin{tabular}{|c|c|c|}
\hline Property & Low PV years of STMW & High PV years for STMW \\
\hline Potential vorticity & $\approx 5 \times 10^{-11}(\mathrm{~ms})^{-1}$ & $\approx 10 \times 10^{-11}(\mathrm{~ms})^{-1}$ \\
\hline Buoyancy flux anomaly & $\leq 2 \times 10^{-5} \mathrm{~kg}\left(\mathrm{~ms}^{3}\right)^{-1}$ & $\geq-2 \times 10^{-5} \mathrm{~kg}\left(\mathrm{~ms}^{3}\right)^{-1}$ \\
\hline SST & $-0.6^{\circ} \mathrm{C} \leq \mathrm{SST}<0$ & $0<\mathrm{SST} \leq 0.5^{\circ} \mathrm{C}$ \\
\hline$\Delta$ SLP (Azores-Iceland) & $-12 \mathrm{mb} \leq \Delta P<0$ & $0<\Delta P \leq 9 \mathrm{mb}$ \\
\hline Gulf Stream position & South of mean location & North of mean location \\
\hline NAO & Low phase & High phase \\
\hline Storm tracks & More zonal, southerly tracks & $\begin{array}{l}\text { More northeasterly tracks with max near Ice- } \\
\text { land }\end{array}$ \\
\hline
\end{tabular}

TABLE 1. Summary of results for low and high STMW regimes. 
TABLE 2. Parameters used in (3) to determine required lateral mixing for the quasi-steady PV balance of STMW.

\begin{tabular}{cccccc}
\hline \hline $\begin{array}{c}\mathrm{PV}_{a} \\
\left(\mathrm{~m}^{-1} \mathrm{~s}^{-1}\right)\end{array}$ & $R(\mathrm{~km})$ & $\Delta R(\mathrm{~km})$ & $f\left(\mathrm{~s}^{-1}\right)$ & $H(\mathrm{~m})$ & {$\left[\begin{array}{c}B_{f} \\
{\left[\mathrm{~kg}\left(\mathrm{~ms}^{3}\right)^{-1}\right]}\end{array}\right.$} \\
\hline $5 \times 10^{-11}$ & 700 & 200 & $10^{-4}$ & 300 & $1 \times 10^{-5}$ \\
\hline
\end{tabular}

terms for the Coriolis frequency $f$, layer thickness $H$, and surface buoyancy flux $B_{f a}$ as presented above in the da Silva et al. atlas. Integrating (2) around a circle of radius $R$ and recognizing that any constant can be subtracted from PV (such as a "background" value) leads to the following

$$
\kappa \mathrm{PV}_{a}=-\frac{R \Delta R}{2} \frac{f}{g \rho_{0} H^{2}} \overline{B_{f a}},
$$

where the subscript " $a$ " refers to the PV or buoyancy flux anomaly (relative to an "outside" value), $\Delta R$ is the scale over which the radial gradient in PV is estimated (at radius $R$ ), and $B_{f a}$ has been averaged over an area $\pi R^{2}$. The time series at Bermuda can be estimated to give $\mathrm{PV}_{a}$, the da Silva et al. atlas can provide the buoyancy flux anomaly, and the Lozier et al. distribution of $\mathrm{PV}$ (Fig. 1) gives $R$ and $\Delta R$ leaving only $\kappa$ to be determined. We have done this using the values in Table 2 and have estimated an eddy mixing coefficient, $\kappa=$ $1.5 \times 10^{3} \mathrm{~m}^{2} \mathrm{~s}^{-1}$.

We could easily change the value of $\kappa$ by changing the area over which the buoyancy flux acts to be different from the total area of the circle of radius $R$, representing the fact that the layer is in direct contact with the atmosphere over only a fraction of the surface area. In this case, the estimate of $\kappa$ would be reduced by the same fraction. As an order of magnitude balance, however, it would seem that diabatic forcing equated to eddy fluxes is plausible since the above estimate of $\kappa$ is not unreasonable based on other studies of mesoscale mixing in the ocean (Robbins et al. 2000, Joyce et al. 1998). Our analysis differs from the balances considered by Hazeleger and Drijfhout (1998) in their model of the subtropical gyre in that they find that summertime detrainment of the mode water into the mixed layer is more important than eddy fluxes. However, their model did not resolve the eddies and had little recirculation of the STMW near Bermuda, so our estimate should be considered an upper bound on $\kappa$. They also find plausible variations in STMW PV based in interannual variations of the heat flux over a period from 1954 to 1978, which spans our two pentads.

\section{b. A new mechanism for a coupled oscillation}

If the Gulf Stream position is responsible for a significant part of the atmospheric forcing, then a possible mode of coupled oscillation may exist for creating selfsustained decadal signals of the sort we have been describing. We first begin in the Labrador Sea, at the end of the mixed layer deepening cycle that occurs in the subpolar gyre (McCartney and Talley 1982). Pickart et al. (1997) have found that during cold winters, convective mixing on the periphery of the Labrador Basin is capable of producing a type of LSW that is injected directly into the western boundary current. During these cold years, LSW is renewed within the Labrador gyre as well. They contrast two years (1966, low heat loss; 1972, high heat loss) in which maximum cooling rates in the winter months vary by a factor of 2 between the two years. The reader will note that these two years are in different pentads for the STMW as well. In 1966 (1972), heat and buoyancy fluxes were large (small) in winter in the subtropical gyre consistent with the correlations presented in Fig. 3. Enhanced LSW production and export in years in which the GS position is north of its mean position, the NAO is in a high phase, and STMW is in a low phase encapsulates the decadal variability in the western North Atlantic based on our findings above.

For the North Atlantic, two important mechanisms are needed to complete the necessary ingredients for a self-sustained oscillation: the air-sea forcing anomalies must be coupled to GS position and the enhanced southward transport of LSW must influence the separation point of the GS off Cape Hatteras. The nature of the atmospheric response to SST anomalies in the Gulf Stream region remains controversial. Atmospheric general circulation modeling experiments by Palmer and Sun (1985), Peng et al. (1995), and Venzke et al. (1999) find a consistent response that resembles the observed SLP anomaly pattern (i.e., Fig. 3). However, not all GCMs obtain such a response (cf. Kushnir and Held 1996 for a review). Recent work by Peng et al. (1997) suggests that the nature of the response depends sensitively upon the representation of feedbacks between the transient eddies and the mean flow, an aspect that is affected by model resolution and quality of the simulated mean climate. In addition, the presence of high internal atmospheric variability in midlatitudes complicates the detection of a relatively weak atmospheric response to extratropical SST anomalies (cf. Venzke et al. 1999). Very recently, Rodwell et al. (1999) have simulated a realistic pattern and amplitude of the NAO in an ensemble integration of a high resolution atmospheric GCM forced by a pattern of SST anomalies in the North Atlantic that closely resembles the observed pattern associated with the NAO (similar to that shown in Fig. 3 ). While not allowing any atmospheric feedback to the ocean, nor taking into account that much of the SST signal is produced by the atmosphere, their study suggests that midlatitude SST signals can influence the atmospheric circulation and the phase of the NAO. Their study did not isolate the effects of SST anomlies along the Gulf Stream path, however. These issues notwithstanding, we wish to explore a simple model in which SST anomalies arising from changes in the Gulf Stream 
path affect the atmospheric circulation in the sense depicted in Figs. 3 and 10.

The influence of transport variations of the Deep Western Boundary Current (DWBC) on Gulf Stream separation was clearly revealed to occur in the layered numerical model of Thompson and Schmitz (1989). They found that the addition of a southward transport of the DWBC moved the separation point of the Gulf Stream southward in their model. This will be discussed further in the next section. Spall (1996a,b) further showed that the presence of a DWBC of LSW could produce decadal variations in Gulf Stream position, deep transport in the recirculation gyres, and the eddies that create them even with a steady southward flow. In these studies, a key diagnostic is the transport of the LSW at the crossover point (Pickart and Smethie 1993) that is far downstream of the Labrador Sea and, which will reflect a time-lagged response to the forcing in the Labrador Basin.

If the volume transport of LSW, represented by $V$, which is exported due to air-sea forcing, $F$ is represented as below

$$
\tau V_{t}+V=F,
$$

then the steady-state balance reflects the net production of LSW. A time-dependent forcing will change the rate of outflow with a response time $\tau$ according to (4). The anomalies of transport and forcing, defined by the departure from the steady-state values, are denoted with subscripts $a$. At the crossover point, the anomaly of the Gulf Stream position, $y_{a}$, is related to the time-lagged transport anomaly of LSW, $V_{a}\left(t-t_{0}\right)$, in the following manner:

$$
y_{a}=-k V_{a}\left(t-t_{0}\right)
$$

where $k$ is a positive constant and the sign is such that a positive transport anomaly will move the separation point southward. Finally, we relate the anomalous forcing to the unlagged position of the Gulf Stream:

$$
F=r y \text {, }
$$

where $r$ is another positive constant reflecting the observed fact that during periods when the Gulf Stream is in a northern (southern) position, the wintertime cooling in the Labrador Basin and subpolar gyre is strong (weak). Finally, we combine (4)-(6) to obtain the following:

$$
\tau V_{t}+V+\beta V\left(t-t_{0}\right)=0,
$$

where all variables have had their $a$ subscripts dropped and we define $\beta=k r$. The relationship in (7) represents a negative, delayed feedback between the volume transport that increases in time due to forcing but, which will ultimately be decreased due to the southward shift of the Gulf Stream once this information is received at the crossover point. The value of $\beta$ represents the strength of the feedback. For small time lags, the feedback term stabilizes the solution, while for larger lags, oscillations can occur. This type of system was shown by Pippard (1985) to be stable in time for small enough values of $\beta$, but to possess oscillatory and eventually exponentially growing solutions when $\beta$ is increased beyond a value of 0.025 . Since the important parameters $\left(\beta, \tau, t_{0}\right)$ define the nature of the solution, we will briefly discuss plausible values for these first.

Mean estimates of the transport of the DWBC (Schmitz and McCartney 1993) are $12 \mathrm{~Sv}$, of which 4 Sv are LSW. Pickart and Smethie (1998) find greater values for both at $55^{\circ} \mathrm{W}: 19$ and $6 \mathrm{~Sv}$, respectively. The latter estimates from 1993 and 1995 represent a high phase of the NAO and suggest that there might be longterm variability in the classical LSW transport, although this is just a conjecture at this stage. The recent measurements do not find a large recirculation indicating it may be absent at that longitude or possibly missed in the sections, in which case there may be less of a discrepancy between the two different estimates attributable to time dependence. As the recent measurements are tied to some direct velocity measurements, we will take these as representing a maximum in transport. We hypothesize that the range of air-sea forcing in the Labrador Basin is such as to double or completely suppress new production of LSW, the transport of the deeper components of the DWBC being held constant. Thus, the total transport in the LSW is $3 \pm 3 \mathrm{~Sv}$. This may seem extreme, and in fact there is no observational time series of LSW transport to guide us, but we will soon see in this simple model that smaller ranges in interannual transport may still trigger oscillations. We have observed a variation in GS position of order $100 \mathrm{~km}$ so we take an amplitude of $\pm 50 \mathrm{~km}$ to be associated with a transport change of $\pm 3 \mathrm{~Sv}$ as representing scales with which to nondimensionalize (4)-(7). The above sensitivity $\left(0.06 \mathrm{~Sv} \mathrm{~km}{ }^{-1}\right)$ is consistent with what is found below in a more detailed three-layer numerical calculation. Thompson and Schmitz underestimated the sensitivity because they had only two layers, with the lower layer four times thicker than the LSW layer we use below. Since only the product $k r$ is dynamically important, we will take it to be the ratio of the latitude excursion and transport scales $\left(17 \mathrm{~km} \mathrm{~Sv}^{-1}\right)$. When inserted into (4), using (5)-(6), we see that a value of 1 for $\beta$, corresponds to a transport change of $6 \mathrm{~Sv}$ due to a latitude change of $100 \mathrm{~km}$. Since, according to Pippard, even small values of $\beta$ lead to oscillations, only a modest degree of coupling between air-sea exchange, hence, transport change to Gulf Stream position is capable of making for nontrivial solutions of (7). We will consider values of $\beta$ in the range $0.01-1$.

Curry et al. (1998) have shown that changes in LSW thickness in the source region can be detected in the subtropical gyre $6 \mathrm{yr}$ later at Bermuda. The pathway is not direct; in fact, LSW anomalies can be seen bifurcating near the tail of the Grand Banks with an eastward pathway into the subpolar gyre and a second pathway in the DWBC toward the crossover point near Cape 
Hatteras. Signals appearing at Bermuda must have followed the latter path and we expect that time delays of a few years might be reasonable to reach the crossover point. The LSW transport decay timescale $\tau$, represents how long the Labrador Sea takes to reach a new steady state. We simply take this to be a number in the range of 1-5 yr and look at the nature of the solutions.

First, one can look for purely oscillatory solutions to (7) (imaginary part of frequency is zero) and show that the lowest frequency of oscillation is given by

$$
\omega t_{0}=\cos ^{-1}(1 / \beta),
$$

which cannot exist for $\beta<1$. Since we are interested in small $\beta$, we expect the relevant solutions be complex in nature. We can solve the coupled equations (4)-(6) numerically from an initial state of zero anomalies, and "force" the system by adding some random white noise to the GS position. For small enough coupling we see (Fig. 11), as predicted by Pippard, that no oscillation develops. For larger values of $\beta$, a self-sustained oscillation develops whose period is independent of $\beta$, but whose amplitude is linearly related to $\beta$. Even for small amplitudes of oscillation, the character of the solution is periodic, but distinctly nonsinusoidal. In appears to be a mode that for $t_{0}$ sufficiently greater than $\tau$, approaches a quasi-steady value corresponding to one of the two extreme states of the system at the peak of each half cycle, before being switched into another exponential mode that brings it back toward zero and then overshoots to the other extreme. The period of this cycling is almost entirely determined by the time delay, having a value of about $2.5 t_{0}$, with $(\tau, \beta)$ not playing any major role in its determination. The nature of the limit cycle in Fig. 12 is such that the GS will attain its northern (southern) extreme, the transport will continue to grow (decay) until a delayed signal appears at the crossover point triggering a switch in the GS position to the other state. The solution is more sawtoothed when $\tau \approx t_{0}$. This negative feedback oscillator can produce decadal oscillations, requires coupling between the ocean and atmosphere, and is consistent with the variability as encapsulated in Table 1. It clearly oversimplifies the real ocean, but is perhaps of some interest to those seeking mechanisms for determining the nature and cause of the NAO. It is a close analog to that suggested for El Niño-Southern Oscillation (ENSO) by Suarez and Schopf (1988), who also found that the period of their oscillator was about $2.5 t_{0}$ as we have here. The novel aspects of this oscillator are that the position not transport of the Gulf Stream is a key. Only processes that occur in the western boundary region are important; no crossbasin oceanic Rossby wave propagation (Latif and Barnett 1994) or downstream advection of temperature anomalies (Groetzner et al. 1998) is involved although both oscillatory modes require an atmospheric response of increased (decreased) westerlies over a cold (warm) SST anomaly.
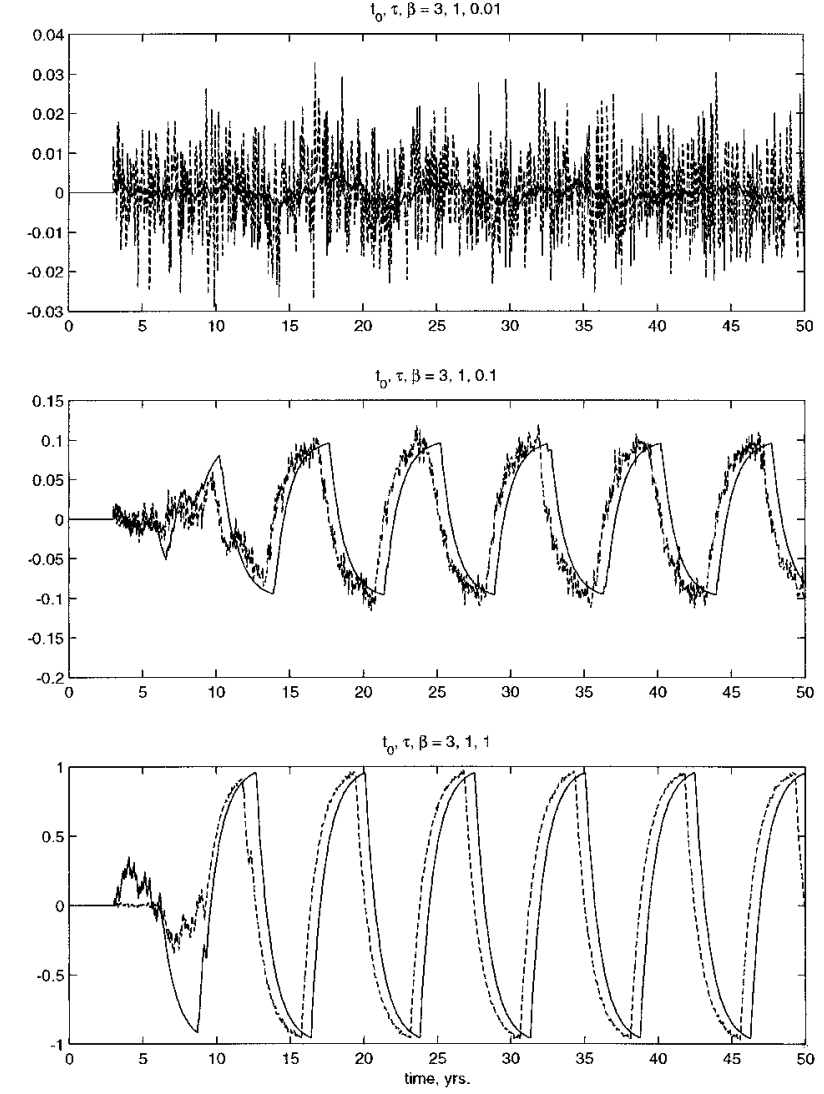

FIG. 12. Normalized position of Gulf Stream (dashed) and normalized LSW transport (solid lines) for three different values of the coupling term $\beta$ as indicated on the figure panels. The values of $\left(t_{0}, \tau\right)$ have been fixed at 3 and $1 \mathrm{yr}$, respectively. In the lower two panels, oscillations develop with a period of 8-9 yr.

\section{c. A numerical model to investigate the coupled oscillation mechanism}

In this section we present results from two types of idealized numerical modeling calculations. A series of coupled runs are carried out in which the transport of the upper DWBC is determined by the position of the Gulf Stream, analogous to the coupling described by the idealized set of equations in section $8 \mathrm{~b}$. These results are compared with a second set of calculations in which the transport of the upper DWBC is specified to vary in time independent of the position of the Gulf Stream.

Our primary interest is to explore the sensitivity of the Gulf Stream separation latitude to variations in the transport of the upper DWBC and the coupling parameters and to determine the strength of coupling required in this model in order to produce large-amplitude, selfsustained oscillations. The model is very idealized and not intended to be comprehensive. A number of processes are neglected that may be important for the variability of the Gulf Stream position and DWBC transports, including surface buoyancy forcing, temporal changes in the wind stress, and changes in the upper ocean component of the thermohaline circulation. 
The primitive equation model described by Thompson and Schmitz (1989) is here configured with three moving isopycal layers representing the main thermocline, an intermediate layer, and a deep layer. The model domain extends $3000 \mathrm{~km}$ in longitude and $2400 \mathrm{~km}$ in latitude with uniform $15-\mathrm{km}$ grid resolution. The model topography is flat everywhere except for a $250 \mathrm{~km}$ wide band along the western boundary where the topography slopes uniformly from 2500 to $5000 \mathrm{~m}$ with slope 0.01 . Subgrid-scale mixing is parameterized through a Laplacian viscosity with mixing coefficient $200 \mathrm{~m}^{2} \mathrm{~s}^{-1}$. The resting layer thicknesses (and potential densities) are 850 (26.25), 900 (27.75), and $3250 \mathrm{~m}$ (27.88).

The model is forced by a steady zonal wind stress applied to the upper layer given by the analytic function:

$\tau_{x}= \begin{cases}-\tau_{m} \cos (\pi y / L), & y<y_{m}, \\ \tau_{m}\left\{1+\cos \left[\pi\left(y-y_{m}\right) /\left(L-y_{m}\right)\right]\right\} / 2, & y>y_{m} .\end{cases}$

The zero wind stress curl occurs at latitude $y_{m}=1200$ $\mathrm{km}$. The maximum wind stress is given by $\tau_{m}$, which will be varied for different experiments. This distribution gives a stronger maximum wind stress curl in the subtropical gyre than in the subpolar gyre, crudely representing the zonally averaged zonal wind stress over the North Atlantic.

The model is also forced through inflow/outflow boundary conditions that represent the upper and lower components of the DWBC. The transport is specified to flow into the model domain through a $225-\mathrm{km}$-wide inflow port in the northwest corner. The DWBC waters are required to exit the model domain through the southern boundary such that total mass within each layer is conserved. There is no cross-isopycnal mass flux within the model domain. The outflow boundary conditions use a radiation condition on the transport normal to the boundary. Details can be found in Thompson and Schmitz (1989). A similar model configuration was used by Spall $(1996 a, b)$ to study the interaction between the Gulf Stream and the DWBC under steady forcing conditions.

\section{1) Coupled Runs}

The model is initially spun up from rest for a period of $20 \mathrm{yr}$ under steady wind forcing and a fixed, specified transport in both the upper and lower DWBC (5 Sv for each component, $1 \mathrm{~Sv}=10^{6} \mathrm{~m}^{3} \mathrm{~s}^{-1}$ ). After the 20-yr spinup, the upper DWBC transport $D$ is determined by

$$
D=D_{0}+\gamma\left(Y_{\mathrm{gs}}-Y_{0}\right),
$$

where $D_{0}$ is the reference transport of the upper DWBC, $\gamma$ is the change in DWBC transport induced by a lateral shift in the position of the Gulf Stream, $Y_{\mathrm{gg}}$ is the timelagged position of the Gulf Stream, and $Y_{0}$ is the reference position of the Gulf Stream at the end of the spinup period (averaged between years 15 and 20). The position of the Gulf Stream is defined as the latitude of maximum zonal velocity averaged between 65 and 450 $\mathrm{km}$ longitude. The general results are not sensitive to the specific definition of the Gulf Stream position. The outflow transport in the upper DWBC layer is the same as the inflow transport so that there is no mass storage within the model domain. A few calculations have been done in which the outflow transport is held fixed at the mean inflow transport while the inflow transport is allowed to vary in time, in which case there is temporary mass storage within the model domain. The main results presented here were found to be not sensitive to this choice for the outflow transport.

The time-lagged position is given by the 1-yr average of the Gulf Stream position beginning at a time lag of $T$ years. The time lag in this model represents the time it takes for any feedbacks in the Gulf Stream position to influence the production of LSW and the time it takes for these changes to be observed as a change in transport in the upper DWBC at the inflow latitude of the model. It should be noted here that there is no direct observational evidence that the transport of LSW changes in connection with increased convective activity over the Labrador Sea, although there is evidence of changes in the properties of the LSW within the DWBC (Pickart and Smethie 1998). The primary parameters to be varied are the coupling strength $\gamma$, the time lag $T$, and the maximum strength of the wind stress $\tau_{m}$.

The mean streamfunction in the upper two layers over the final $50 \mathrm{yr}$ of a 100-yr integration is shown in Fig. 13 for a coupled run with parameters $\tau_{m}=1 \mathrm{dyn} \mathrm{cm}^{-2}$, $\gamma=0.1 \mathrm{~Sv} \mathrm{~km}{ }^{-1}$, and $T=5 \mathrm{yr}$. The upper layer circulation is dominated by the wind-driven subtropical and subpolar gyres, the separated Gulf Stream, and inertial recirculation gyres to the north and south of the Gulf Stream. The maximum Gulf Stream transport in the upper layer is approximately $80 \mathrm{~Sv}$. The Gulf Stream separates approximately $200 \mathrm{~km}$ south of the zero wind stress curl line as a result of interactions with the DWBC (see also Thompson and Schmitz 1989; Spall 1996a,b). The intermediate layer circulation is dominated by the DWBC and the inertial recirculation gyres. The DWBC is deflected off the western boundary where it crosses under the Gulf Stream, splitting into mean paths flowing eastward under the Gulf Stream and southward along the western boundary. The dynamics of this bifurcation of the DWBC are discussed in Spall (1996a).

The location of the Gulf Stream axis as a function of longitude (out to $1200 \mathrm{~km}$ ) and time is shown in Fig. 14a. After the active coupling is turned on at year 20, the Gulf Stream position oscillates with a period of approximately $11 \mathrm{yr}$. The period is close to twice the time lag of $5 \mathrm{yr}$, slightly longer because it takes some time for the changes in DWBC transport at the inflow to be felt at the crossover. The peak to peak variations in the latitude of the stream are greater than $200 \mathrm{~km}$. The rms variability of the Gulf Stream separation point (defined as the average Gulf Stream latitude between 0 and 200 $\mathrm{km}$ longitude) is $45 \mathrm{~km}$. The Gulf Stream position varies 

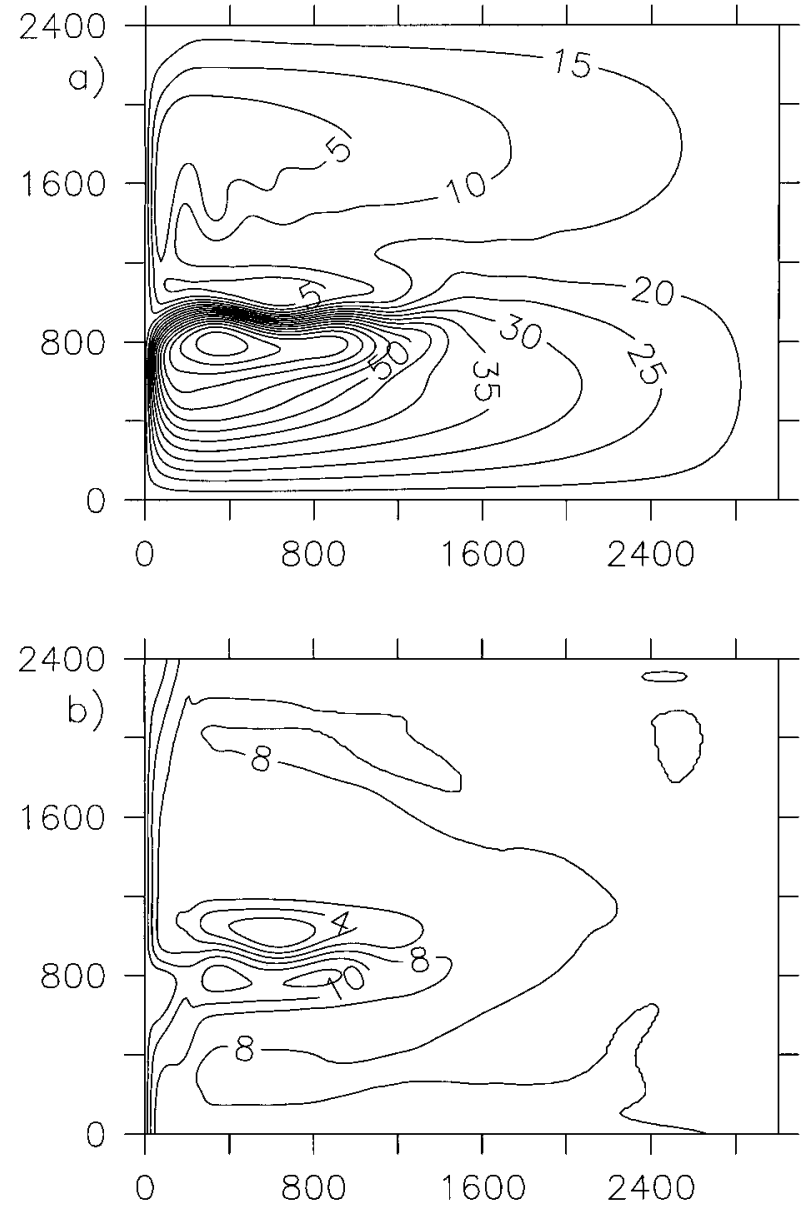

FIG. 13. Mean transport streamfunction (Sv) between yr 50 and 100 for (a) the upper layer and (b) the middle layer with parameters $\tau_{m}=1$ dyn $\mathrm{cm}^{-2}, T=5 \mathrm{yr}, \gamma=0.1 \mathrm{~Sv} \mathrm{~km}{ }^{-1}$.

most strongly within $300 \mathrm{~km}$ of the western boundary, however coherent translations of the Gulf Stream position are found extending to greater than $1000 \mathrm{~km}$ into the basin, approximately over the entire extent of the model Gulf Stream.

The transport in the upper DWBC as a function of time is shown in Fig. 14b. The mean over the entire 100 -yr integration is $5.04 \mathrm{~Sv}$, very close to the initially specified $5 \mathrm{~Sv}$. However, the amplitude of the transport fluctuates strongly between 0 and over $10 \mathrm{~Sv}$ (rms variability is $2.9 \mathrm{~Sv}$ ) with a period of approximately $11 \mathrm{yr}$. The DWBC transport lags the Gulf Stream position such that the transport is maximum (minimum) approximately $5 \mathrm{yr}$ after the Gulf Stream is in its northernmost (southernmost) position.

The strength of the oscillation in the Gulf Stream position and DWBC transport depends strongly on the coupling strength $\gamma$ and the time lag $T$. Figure 15a shows results from a series of $100-\mathrm{yr}$ calculations in which the coupling parameter is varied while holding the time lag fixed at 3 yr. Two sets of calculations are included, one with $\tau_{m}=1$ dyn $\mathrm{cm}^{-2}$ and one with $\tau_{m}=0.75 \mathrm{dyn}$
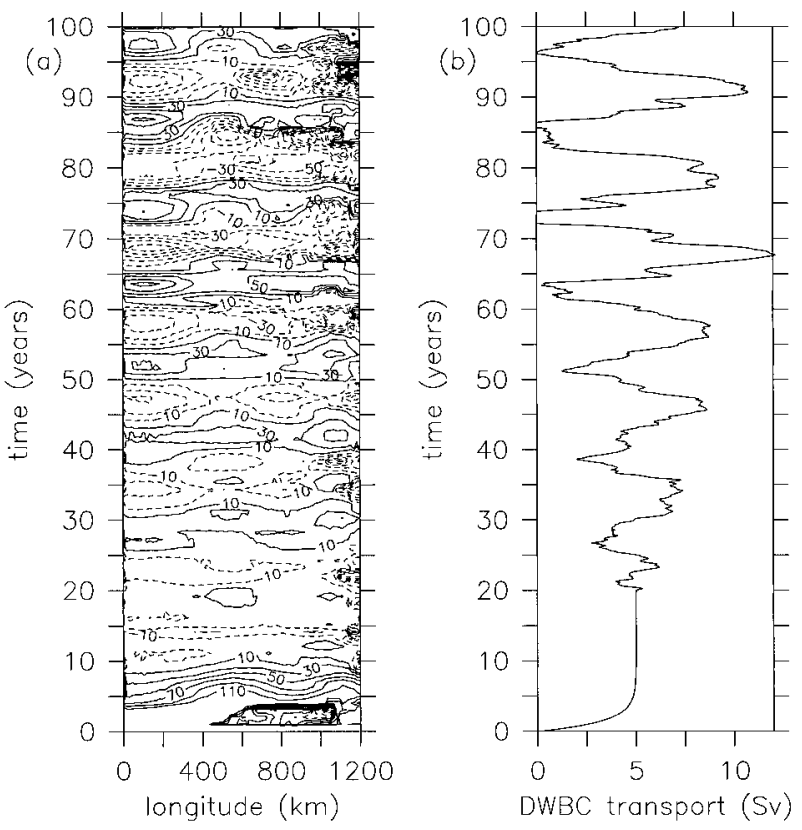

FIG. 14. (a) Deviation of the Gulf Stream axis from its mean position as a unfunction of time and longitude for the coupled run in Fig. 14. Anomalies are relative to the mean between the years of 20 and 100; contour interval is $10 \mathrm{~km}$ with positive (negative) excursions as solid (dashed) lines (b) upper DWBC transport as a function of time, coupling was turned on at year 20 .

$\mathrm{cm}^{-2}$. The natural variability of the Gulf Stream separation latitude in the absence of any active coupling is approximately $12 \mathrm{~km}$ for both values of the wind stress. The variability is not appreciably larger than the natural variability in the uncoupled system for weak coupling of strength $\gamma<0.05$. Oscillations much larger than the natural variability appear only when the coupling strength is $\gamma \approx O(0.1)$, which corresponds to a change of DWBC transport of $10 \mathrm{~Sv}$ for a lateral shift in the Gulf Stream position of $100 \mathrm{~km}$.

The variability in the separation point of the Gulf Stream is also dependent on the time lag $T$ in the coupling between the DWBC transport and the position of the Gulf Stream, as shown in Fig 15b. (The period of the oscillation is approximately twice the time lag.) Very rapid feedback between the position of the Gulf Stream and the transport in the DWBC reduces the variability of the separation point. With the strongest wind stress $\left(\tau_{m}=1.0\right)$, the variability in the coupled case is less than the natural variability in the uncoupled run. This is consistent with the stabilizing influence that one would expect for zero time lag. Increased time lag results in increased variability because this allows the anomalous DWBC transport more time to cause a shift in the separation point of the Gulf Stream before the feedback alters the DWBC transport. Because the separation point does not continue to drift unbounded away from the zero wind stress curl line for an anomalous 

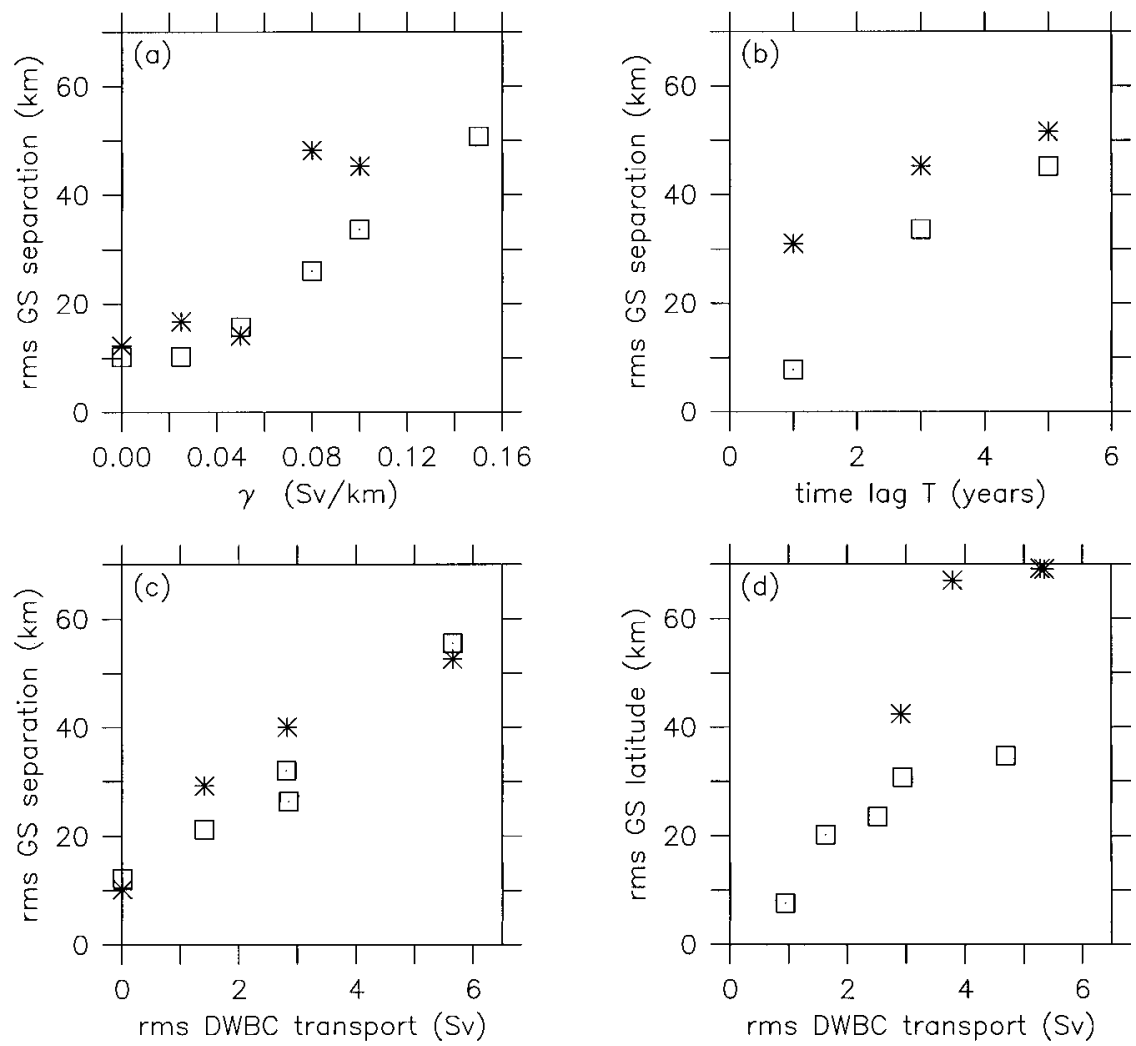

FIG. 15. Root-mean-square variability of the Gulf Stream separation point (defined as the average Gulf Stream position between 0 and $200 \mathrm{~km}$ longitude). The symbols indicate the value of the maximum wind stress: squares for $\tau_{m}=1 \mathrm{dyn} \mathrm{cm}^{-2}$ and stars for $\tau_{m}=0.75 \mathrm{dyn} \mathrm{cm}^{-2}$. (a) Sensitivity to the strength of the coupling between the Gulf Stream position and variations in DWBC transport, $\gamma$ with $T=3 \mathrm{yr}$. (b) Sensitivity to the time lag $T$ with $\gamma=0.1 \mathrm{~Sv} \mathrm{~km}{ }^{-1}$. (c) Variability of the separation latitude for uncoupled calculations in which the transport of the upper DWBC is specified to vary sinusoidally with a period of $10 \mathrm{yr}$ and amplitude as indicated in the figure. (d) Variability of the Gulf Stream latitude (defined as the average latitude of the Gulf Stream axis between the western boundary and the longitude where the maximum zonal velocity drops below $80 \%$ of its maximum value) as a function of the variability in DWBC transport for all coupled calculations with $\gamma \geq 0.08 \mathrm{~Sv} \mathrm{~km}^{-1}$.

DWBC transport, it is expected that the variability should level off for large $T$, as found here.

\section{2) UNCOUPLED RUNS}

The coupled runs indicate that a feedback between the Gulf Stream position and the transport in the upper DWBC can result in self-sustaining oscillations if the coupling is sufficiently strong. A series of uncoupled experiments has been carried out in which the transport of the upper DWBC is varied sinusoidally with specified period and amplitude.

The variability of the Gulf Stream separation point as a function of the variability in the upper DWBC transport is shown in Fig $15 \mathrm{c}$ for a series of $100-\mathrm{yr}$ calculations in which the amplitude of the upper DWBC transport is varied sinusoidally with a period of $10 \mathrm{yr}$. There is a nearly linear relationship between the variability in the DWBC transport and the variability in the separation latitude of the Gulf Stream. The rms variability in the Gulf Stream separation latitude $\delta Y_{s}(\mathrm{~km})$ may be related to the rms variability in the DWBC transport $\delta D(\mathrm{~Sv})$ through a linear least squares fit of the form

$$
\delta Y_{s}=a+b \delta D .
$$

The natural variability in the separation point with a steady upper DWBC transport is $a$ and the increase in variability of the separation point as a result of increasing variability in DWBC transport is $b$. A least squares fit to the model data points gives $a=12.5 \mathrm{~km}$ and $b$ $=7.4 \mathrm{~km} \mathrm{~Sv}^{-1}$ with a standard deviation of $4.3 \mathrm{~km}$, corresponding to a nondimensionalized $\beta=0.41$. The frequency of the oscillations in Gulf Stream position is determined by the period of the variations in DWBC transport. The amplitude of the response to variations in DWBC transport is only weakly dependent on this frequency as long as the period is several years or longer, 
similar to the sensitivity to the time lag for the coupled model in Fig 15b. The variability decreases considerably for variations in DWBC transport with a period of $1 \mathrm{yr}$.

These results can be used to understand the sensitivity of the oscillations in the coupled model to the strength of the coupling parameter $\gamma$. Low-frequency variations in the DWBC transport influence the separation point of the Gulf Stream by an amount $b \delta D$, regardless of what is responsible for the change in DWBC transport. The sensitivity of the Gulf Stream position to changes in the DWBC transport must be sufficiently strong if the coupled model is to produce self-sustaining oscillations that are larger than the natural variability of the Gulf Stream. For example, if the Gulf Stream shifts by an amount $\delta Y$ due to its own natural variability, the coupled model would produce a change in the DWBC transport of $\gamma \delta Y$. The model responds to this change by shifting the separation point of the Gulf Stream by an amount $b \gamma \delta Y$. If $b \gamma \ll 1$, then the resulting shift of the Gulf Stream will not return it to its original latitude and the oscillation amplitude will be smaller than the uncoupled variability. If $b \gamma \approx 1$, then the Gulf Stream will shift back to its original position and the oscillation will be comparable to the uncoupled variability. For $b \gamma$ $\gg 1$ the coupled oscillation becomes larger than the original perturbation and it will grow to dominate the variability. This is consistent with the rapid increase in variability of the coupled system near $\gamma=0.1$, where $b \gamma=0.74$.

Variations in the Gulf Stream separation point would most strongly influence the atmosphere if the latitude of the Gulf Stream were also impacted far from the separation point, as in Fig. 6. Although the variability in Gulf Stream position is strongest near the western boundary of the model, Fig. 13 clearly shows that there is a penetration of this signal far into the ocean interior. The Gulf Stream latitude is defined as the average latitude of the Gulf Stream axis over the entire penetration distance of the Gulf Stream. The penetration scale is defined here to be the longitude where the zonal velocity drops below $80 \%$ of its maximum value. For the calculation in Fig. 13, the average penetration scale is 960 $\mathrm{km}$. The penetration scale varies between 400 and 1100 $\mathrm{km}$ over all of the calculations. The dependence of the Gulf Stream latitude on the variability in the upper DWBC transport is shown in Fig. 15d for all coupled model runs with $\gamma \geq 0.08$. The trend of increasing variability in Gulf Stream position with increasing variability in upper DWBC transport is retained over the entire zonal length scale of the Gulf Stream. This is found for both the coupled and uncoupled runs. A least squares fit results in $a=10.4 \mathrm{~km}$ and $b=8.2 \mathrm{~km} \mathrm{~Sv}^{-1}$ with a standard deviation of $13.7 \mathrm{~km}$. The slope of the least square fit line is partly determined by the choice of coupling parameter as $b \approx \gamma^{-1}$. There is a slight difference because the diagnosed position of the Gulf Stream used to determine the DWBC transport is dif- ferent from the average position over the entire penetration scale of the Gulf Stream.

The simple model formulation used here identifies several important features of the midlatitude oceanic response to low-frequency variability in the thermohaline circulation. First, we have demonstrated that the Gulf Stream changes latitude in response to low-frequency variations in the DWBC transport. The magnitude of this variability in the model is consistent with the observed variability in Gulf Stream position between the pentads discussed earlier (approximately 50-100 $\mathrm{km})$ and variability of DWBC of $O(5 \mathrm{~Sv})$. This response also quantifies the approximate "coupling" strength between shifts in the Gulf Stream position and deep western boundary transport that would be required in order for the system to support self-sustaining oscillations. Finally, the model calculations also showed that the interactions between the Gulf Stream and the DWBC near the separation point cause a large-scale (approximately $1000 \mathrm{~km}$ ) coherent shift in the Gulf Stream latitude well into the basin interior. This is also consistent with the longitude over which the Gulf Stream was found to shift position in Fig. 6.

\section{Summary}

We briefly summarize the findings of our work as a list of major results using data from the years 1954-89 inclusive.

- Interannual variability of the STMW potential vorticity is correlated with atmospheric buoyancy forcing and in phase as if the ocean were passively driven with eddies doing the damping.

- Associated with this STMW variability, the largescale atmospheric SLP signal resembles the spatial pattern of the NAO and an NAO index is correlated in time with STMW PV with no temporal phase lag between the two.

- Gulf Stream position also shifts interannually with the STMW/NAO and the maximum correlation occurs at zero phase lag between the GS/NAO/STMW PV, although the GS is as highly correlated with the NAO at a lag of $1 \mathrm{yr}$ as at 0 lag.

- Pentadal analysis of climatological extremes of STMW PV show north-south shifts in the GS position, the latitude of the zero wind stress curl, and the extratropical winter storm tracks.

- If GS position can affect the air-sea exchange, then a feedback loop can be established in which the control of GS position by the DWBC transport at the crossover point produces decadal oscillations of the GS and the air-sea fluxes controlling both the source waters of the DWBC in the Labrador Sea and the STMW in the Sargasso Sea.

- Model calculations suggest that this feedback mechanism is capable of creating self-sustaining oscillations only if the degree of coupling between GS lat- 
itude and LSW transport variability is moderately robust.

Our model results have demonstrated necessary, but not sufficient, conditions for such an active coupling between the ocean and atmosphere. While the sensitivity found in the model is consistent with the observed variability, we can not conclude that there must be an active feedback through the atmosphere. It is possible that the low-frequency variability in both the Gulf Stream and the formation of LSW are being forced by the atmosphere independent of each other. It is also possible that the observed variability in Gulf Stream position is a consequence of low-frequency variability in the strength of the thermohaline circulation, but that the resultant changes in SST have no discernable effect on the position of atmospheric storm tracks. While it is beyond the scope of the present study to resolve these issues, we feel that the present results provide useful insight into the midlatitude oceanic response to low-frequency variability in the thermohaline circulation and hope that they will stimulate further research into possible midlatitude coupling mechanisms.

We recognize that the NAO system is more complicated than our simple model assumes (low salinity anomalies capping the Labrador Sea, for example) and admit that our assumption of a strong atmospheric coupling to Gulf Stream SST anomalies is speculative. It is also clear from our findings that the shortness of the record and the long timescale of the variability limits the statistical confidence which can be brought to bear. Work is currently underway to extend our analyses another decade within the next year using data from the 1990s.

Acknowledgments. This work is part of the WOCE effort within the Atlantic Circulation and Climate Experiment, and is supported by NSF Grants OCE9529607 (TJ), OCE95-31870 (CD), and OCE95-31874 (MS). Thanks go to J. Dunworth-Baker and R. Goldsmith who helped with some of the various data extractions, for assistance from M. Timlin using the GrADs software package, and to C. Frankignoul, for several discussions. A. Taylor provided some unpublished data as well as comments, with another anonymous reviewer, on an early draft of this manuscript.

\section{APPENDIX}

\section{Comparison of Two Different Indices of Gulf Stream Position}

In order to address the reasons why our results on mean Gulf Stream position and its correlation with the NAO differ from those published by Taylor and Stephens, Taylor provided us with his annual mean Gulf Stream data from longitudes $79^{\circ}, 75^{\circ}, 72^{\circ}, 70^{\circ}, 67^{\circ}$, and $65^{\circ} \mathrm{W}$ for the period $1966-98$, inclusive. Note that these are different positions than we have used and that the

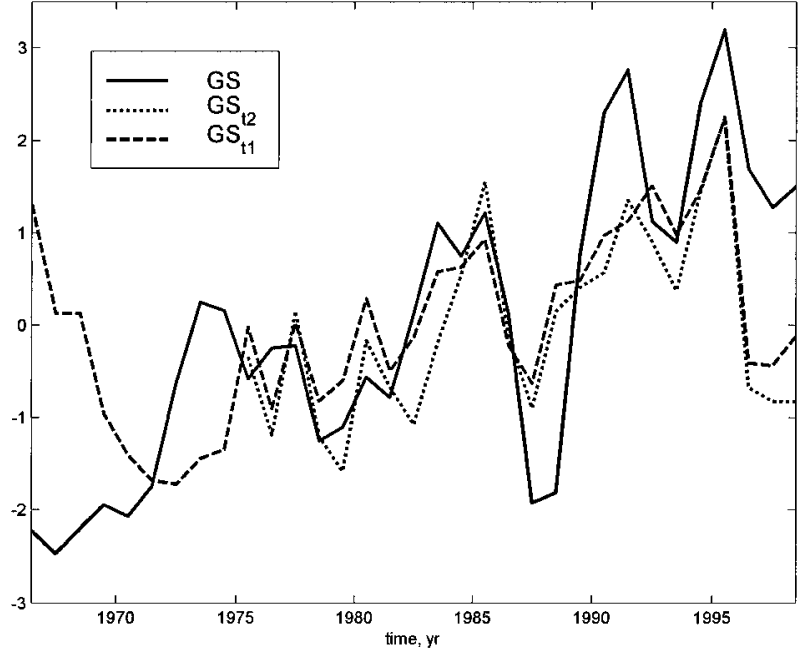

FIG. A1. The GS index used in this study (solid curve) compared with two versions of the GS index based on data from A. H. Taylor (1999, personal communication; long and short dashed curves) for a more recent time period (1966 or 1975-98). The Taylor indices are based on annual mean data for the full time period $\left(\mathrm{GS}_{t 1}\right)$ and for the post-1974 time period $\left(\mathrm{GS}_{t 2}\right)$.

time interval is different. Because we contend that the first years of the Taylor estimate are different from ours, we have updated our Gulf Stream (and NAO) estimates through 1998 to overlap with the Taylor frontal analysis data. We have analyzed the $T(200 \mathrm{~m})$ and frontal analysis datasets similarly, using the covariance matrix (not correlation matrix) for our comparisons. In our previ-

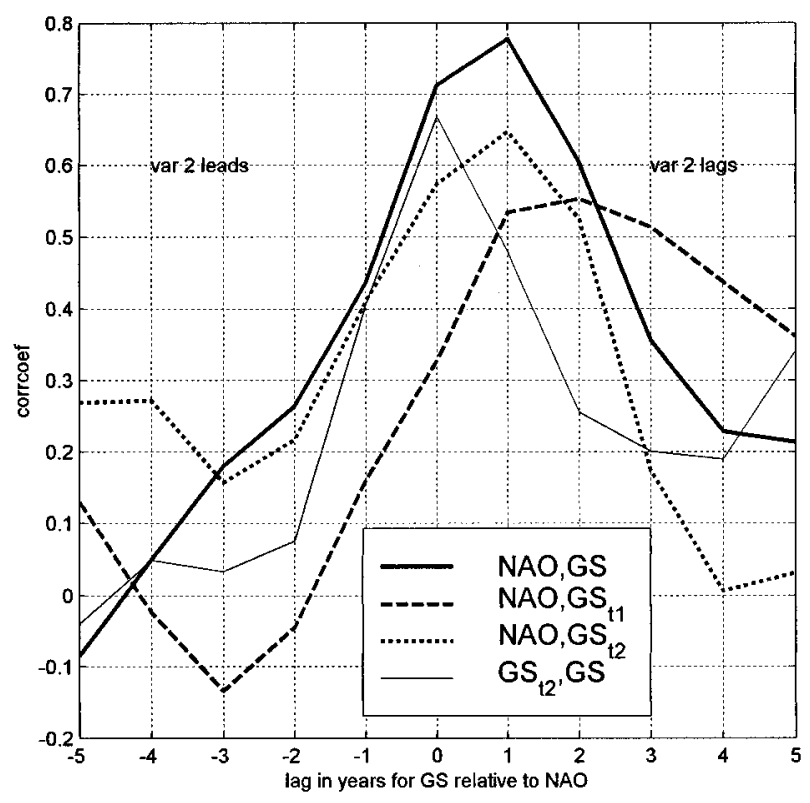

FIG. A2. Lagged cross correlations between the NAO and the GS indices shown in Fig. A1. The lag correlation between the GS index used in this study and that based on data from Taylor for the period 1975-98 (thin solid curve) indicates the two to be correlated with no time lag. 
ously described work above, we have felt that the covariance method, which gives more weight to the more energetic longitudes, is more appropriate since that is what the atmosphere sees. We have made two different estimates from the Taylor data: one using the whole dataset and the other excluding data before 1973. The results are shown in Fig. A1 for the leading EOFs, which typically contain about $50 \%$ of the variance in the covariance matrices. We have further compared the lagged correlation of the various time series (including an updated, smoothed NAO) in Fig. A2.

First of all, we can see the discrepancy between Taylor's 1966-98 leading EOF and ours, which is based on $9^{\circ}$ longitudes between $75^{\circ}$ and $55^{\circ} \mathrm{W}$. The overlapping two time series of the Taylor estimate with and without the pre-1975 data are slightly different because of the different longitudinal loading in the EOFs. It is clear that our GS estimate and that of Taylor's shorter estimate are both most highly correlated with the NAO at 0 - and 1 -yr lags, with the maximum correlation now at $1-\mathrm{yr}$ lag compared to 0- and 1-yr lags when the period 195589 is used (recall Fig. 8). The longer Taylor record exhibits maximum correlation with the NAO at lags 1-3 $\mathrm{yr}$; however, we maintain that this is due to some peculiarities of the frontal analysis data in the initial years that we cannot explain.

\section{REFERENCES}

Battisti, D. S., U. S. Bhatt, and M. A. Alexander, 1995: A modeling study of the interannual variability in the wintertime North Atlantic Ocean. J. Climate, 8, 3067-3083.

Behrenger, D., L. Regier, and H. Stommel, 1979: Thermal feedback on wind stress as a contributing cause of the Gulf Stream. $J$. Mar. Res., 37, 699-709.

Bower, A. S., H. T. Rossby, and J. L. Lillibridge, 1985: The Gulf Stream-barrier or blender. J. Phys. Oceanogr., 15, 24-32.

Cayan, D. R., 1992: Latent and sensible heat flux anomalies over the northern oceans: Driving the sea surface temperature. J. Phys. Oceanogr., 22, 859-881.

Cornillon, P., 1986: The effect of the New England Seamounts on Gulf Stream meandering as observed from satellite IR imagery. J. Phys. Oceanogr., 16, 386-389.

Curry, R. G., M. S. McCartney, and T. M. Joyce, 1998: Oceanic transport of subpolar climate signals to mid-depth subtropical waters. Nature, 391, 575-577.

da Silva, A. M., and S. Levitus, 1994: Algorithms and procedures. Vol. 1, Atlas of Marine Data 1994, NOAA Atlas NESDIS, 83 pp.

Deser, C., and M. L. Blackmon, 1993: Surface climate variations over the North Atlantic Ocean during winter: 1900-1989. J. Climate, 6, 1743-1753.

_ , and M. S. Timlin, 1997: Atmosphere-ocean interaction on weekly timescales in the North Atlantic and Pacific. J. Climate, 10, 393-408.

Dickson, R., J. Lazier, J. Meinke, P. Rhines, and J. Swift, 1996: Longterm coordinated changes in the convective activity of the North Atlantic. Progress in Oceanography, Vol. 38, Pergamon, 241295 .

Fieux, M., and H. Stommel, 1975: Preliminary look at feasibility of using marine reports of sea surface temperature for documenting climatic change in the western North Atlantic. J. Mar. Res., 33, 83-95.

Frankignoul, C., and K. Hasselman, 1977: Stochastic climate models.
Part II: Application to sea-surface temperature anomalies and thermocline variability. Tellus, 29, 289-305.

Fuglister, F. C., 1955: Alternate analyses of current surveys. DeepSea Res., 2, 213-229.

_ 1963: Gulf Stream '60. Progress in Oceanography, Vol. 1, Pergamon, 265-373.

Gangopadhyay, A., P. Cornillon, and R. D. Watts, 1992: A test of the Parsons-Veronis hypothesis on the separation of the Gulf Stream. J. Phys. Oceanogr., 22, 1286-1301.

George, D. G., and A. H. Taylor, 1995: U.K. lake plankton and the Gulf Stream. Nature, 378, 139.

Groetzner, A., M. Latif, and T. P. Barnett, 1998: A decadal climate cycle in the North Atlantic Ocean as simulated by the ECHO coupled GCM. J. Climate, 11, 831-847.

Halkin, D., and T. Rossby, 1985: The structure and transport of the Gulf Stream at $73^{\circ}$ W. J. Phys. Oceanogr., 15, 1439-1452.

Halliwell, G. R., Jr., 1998: Simulation of North Atlantic decadal/ multidecadal winter SST anomalies driven by basin-scale atmospheric circulation anomalies. J. Phys. Oceanogr., 28, 5-21.

- and C. N. K. Mooers, 1979: The space-time structure and variability of the Shelf Water-Slope Water and Gulf Stream surface temperature fronts and associated warm-core eddies. J. Geophys. Res., 84, 7707-7725.

Hazeleger, W., and S. S. Drijfhout, 1998: Mode water variability in a model of the subtropical gyre: Response to anomalous forcing. J. Phys. Oceanogr., 28, 266-288.

Hurrell, J. W., 1995: Decadal trends in the North Atlantic Oscillation: Regional temperatures and precipitation. Science, 269, 676-679.

Joyce, T. M., and P. E. Robbins, 1996: The long-term hydrographic record at Bermuda. J. Climate, 9, 3121-3131.

_ J. R. Luyten, A. Kubryakov, F. B. Bahr, and J. S. Pallant, 1998: Meso- to large-scale structure of subducting water in the subtropical gyre of the eastern North Atlantic Ocean. J. Phys. Oceanogr., 28, 40-61.

Kushnir, Y., and I. M. Held, 1996: On the equilibrium atmospheric response to North Atlantic SST anomalies. J. Climate, 9, 12081220.

Latif, M., and T. P. Barnett, 1994: Causes of decadal variability over the North Pacific and North Atlantic. Science, 266, 634-637.

Levitus, S., 1989: Interpentadal variability of temperature and salinity at intermediate depths of the North Atlantic ocean, 1970-1974 versus 1955-1959. J. Geophys. Res., 94, 6091-6131.

— 1994: World Ocean Atlas 1994, National Oceanographic Data Center, CD-ROM sets, Informal Rep. 13, disk 8.

Lozier, M. S., W. B. Owens, and R. G. Curry, 1995: The climatology of the North Atlantic. Progress in Oceanography, Vol. 36, Pergamon, 1-44.

McCartney, M. S., and L. D. Talley, 1982: The subpolar mode water of the North Atlantic Ocean. J. Phys. Oceanogr., 12, 1169-1188.

Molinari, R. L., D. A. Mayer, J. F. Festa, and H. F. Bezdek, 1997: Multiyear variability in the near-surface temperature structure of the midlatitude western North Atlantic Ocean. J. Geophys. Res., 102, 3267-3278.

Palmer, T. N., and Z. Sun, 1985: A modelling and observational study of the relationship between sea surface temperature in the northwest Atlantic and the atmospheric general circulation. Quart. J. Roy. Meteor. Soc., 111, 947-975.

Pedlosky, J., 1979: Geophysical Fluid Dynamics. Springer-Verlag, 624 pp.

Peng, S., L. Mysak, H. Ritchie, J. Derome, and B. Bugas, 1995: The difference between early and midwinter responses to sea surface temperature anomalies in the northwest Atlantic. J. Climate, 8, $137-157$.

— - W. Robinson, and M. Hoerling, 1997: The modeled atmospheric response to midlatitude SST anomalies and its dependence on background circulation states. J. Climate, 10, 971-987.

Pickart, R. S., and W. M. Smethie, 1993: How does the deep western boundary current cross the Gulf Stream? J. Phys. Oceanogr., 23, 2602-2616.

_ and - 1998: Temporal evolution of the deep western bound- 
ary current where it enters the subtropical domain. Deep-Sea Res., 45, 1053-1083.

_ M. A. Spall, and J. R. Lazier, 1997: Mid-depth ventilation in the western boundary current system of the subpolar gyre. DeepSea Res., 6, 1025-1054.

Pippard, A. B., 1985: Response and Stability. Cambridge University Press, $228 \mathrm{pp}$.

Qiu, B., and R. X. Huang, 1995: Ventilation of the North Atlantic and North Pacific: Subduction versus obduction. J. Phys. Oceanogr., 25, 2374-2390.

Rhines, P. B., and W. R. Young, 1982: Homogenization of potential vorticity in planetary gyres. J. Fluid Mech., 122, 347-367.

Robbins, P. E., W. Jenkins, B. Owens, and J. Price, 2000: The importance of lateral diffusion for the ventilation of the lower thermocline in the subtropical North Atlantic. J. Phys. Oceanogr., 30, 67-89.

Rodwell, M. J., D. P. Rowell, and C. K. Folland, 1999: Oceanic forcing of the wintertime North Atlantic Oscillation and European climate. Nature, 398, 320-323.

Rogers, J. C., 1990: Patterns of low-frequency monthly sea level pressure variability (1899-1986) and associated wave cyclone frequencies. J. Climate, 3, 1364-1379.

Rossby, T., and E. Gottlieb, 1998: The Oleander project: Monitoring the variability of the Gulf Stream and adjacent waters between New Jersey and Bermuda. Bull. Amer. Meteor. Soc., 79, 5-18.

Schmitz, W. J., and M. S. McCartney, 1993: On the North Atlantic Circulation. Rev. Geophys., 31, 29-49.

Serreze, M. C., F. Carse, R. G. Barry, and J. C. Rogers, 1997: Icelandic low activity: Climatological features, linkages with the NAO, and relationships with recent changes in the Northern Hemispheric circulation. J. Climate, 10, 453-464.

Spall, M. A., 1996a: Dynamics of the Gulf Stream/deep western boundary current crossover. Part I: Entrainment and recirculation. J. Phys. Oceanogr., 26, 2152-2168.

— 1996 b: Dynamics of the Gulf Stream/deep western boundary current crossover. Part II: Low-frequency internal oscillations. J. Phys. Oceanogr., 26, 2169-2182.

Sturges, W., and B. G. Hong, 1995: Wind forcing of the Atlantic thermocline along $32^{\circ} \mathrm{N}$ at low frequencies. J. Phys. Oceanogr., 25, 1706-1715.

Suarez, M. J., and P. S. Schopf, 1988: A delayed action oscillator for ENSO J. Atmos. Sci., 45, 3283-3287.

Sutton, R. T., and M. R. Allen, 1997: Decadal predictability of North Atlantic sea surface temperature and climate. Nature, 388, 563567.

Talley, L. D., 1996: North Atlantic circulation and variability, reviewed for the CNLS Conference. Physica D, 98, 625-646.

- , and M. E. Raymer, 1982: Eighteen degree water variability. $J$. Mar. Res., 40, 757-775.

Taylor, A. H., 1996: North-south shifts of the Gulf Stream: Ocean atmosphere interactions in the North Atlantic. Int. J. Climatol., 16, 559-583.

—, and J. A. Stephens, 1998: The North Atlantic oscillation and the latitude of the Gulf Stream. Tellus, 50A, 134-142.

Thompson, J. D., and W. J. Schmitz, 1989: A limited area model of the Gulf Stream: Design, initial experiments, and model-data intercomparison. J. Phys. Oceanogr., 19, 791-814.

U.S. Navy, and Dept. of Commerce, 1996: Global Tropical/Extratropical Cyclone Climate Atlas Version 2.0. Fleet Numerical Meteorology and Oceanography Detachment and National Climatic Data Center.

Venzke, S., M. Allen, R. Sutton, and D. Rowell, 1999: The atmospheric response over the North Atlantic to decadal changes in sea surface temperature. J. Climate, 12, 2562-2584.

Worthington, L. V., 1959: The 18 degree water in the Sargasso Sea. Deep-Sea Res., 5, 297-305. 